\title{
The health consequences of excess emissions: Evidence from Texas*
}

\author{
Alex J. Hollinsgworth, David M. Konisky, Nikolaos Zirogiannis ${ }^{\dagger}$
}

March 2021

\begin{abstract}
Excess emissions are air pollution releases that exceed permitted levels and occur during facility start-ups, shutdowns, or malfunctions. While they are violations of the federal Clean Air Act, states have historically granted violating facilities automatic exemptions; limiting enforcement and weakening existing regulation. Recent efforts to harmonize state and federal rules have ignited debate surrounding optimal excess emissions regulation. Using Texas data from 2002-2017, we show robust evidence on the costs of excess emissions. We find that excess emissions increase harmful nearby pollution and elderly mortality, and are responsible for an average of 35 annual deaths in Texas alone. Using excess emissions as an instrument for ozone concentrations, we find that a $10 \%$ increase in monthly average ozone increases elderly mortality by $3.9 \%$, driven by increased deaths in the oldest age groups.
\end{abstract}

Keywords: excess emissions, air pollution, mortality

${ }^{*}$ We would like to thank participants of the Indiana University Paul O'Neill School of Public and Environmental Affairs Summer Research Workshop and PhD health workshop. We also thank Andrew Chupp, Xavier Pautrel, Justin Ross, Ivan Rudik, Jay Shimshack, and numerous conference participants for their feedback and suggestions.

${ }^{\dagger}$ Hollingsworth is an Assistant Professor at the Paul O’Neill School of Public and Environmental Affairs at Indiana University hollinal@indiana. edu; David M. Konisky is a Professor at the Paul O'Neill School of Public and Environmental Affairs at Indiana University, Email: dkonisky@indiana.edu, and Nikolaos Zirogiannis is an Assistant Professor at the Paul O'Neill School of Public and Environmental Affairs at Indiana University, Email: nzirogia@indiana.edu. The authors declare no known conflicts of interest, financial or otherwise, related to this work. 
Over the past half century, the U.S. Environmental Protection Agency (EPA) has pursued a broad portfolio of policies to improve air quality across the country. These efforts, mainly under the framework of the Clean Air Act, span a wide range of regulatory mechanisms including setting and enforcing ambient air quality standards for criteria air pollutants; promulgating source-level pollution control technology requirements; establishing and maintaining a network of air quality monitoring stations; and tracking emissions of harmful pollutants. By most conventional metrics, these federal efforts, bolstered by state and local governments, have generated enormous dividends. Since the passage of the Clean Air Act in 1970, ambient pollutant concentrations and pollutant emissions have decreased (Environmental Protection Agency 2017, Hand et al. 2012, Lin, Jacob and Fiore 2001, Selden, Forrest and Lockhart 1999) and retrospective analyses have found that the benefits of reduced pollution are much higher than associated abatement costs, with the majority of benefits attributable to improved health (Environmental Protection Agency 1997; 1999b).

Despite these achievements, there are a number of persistent issues related to air pollution regulation, including interstate air pollution (Monogan, Konisky and Woods 2017, Revesz and Leinke 2016), areas with persistent air quality problems (e.g., southern California), and disparities in exposure for vulnerable subpopulations (Brooks and Sethi 1997, Miranda et al. 2011, MorelloFrosch, Pastor and Sadd 2001, Colmer et al. 2020, Currie, Voorheis and Walker 2020). Another important area of air pollution regulation that has largely been under-studied and poses important threats to health and environmental quality is excess emissions.

Excess emissions are defined as releases above permitted levels that occur due to start-ups, shutdowns, or malfunctions (Environmental Protection Agency 2015) and these emissions are due to a wide variety of causes ranging from avoidable large-scale accidents (e.g. explosions) to the unavoidable need to shutdown a plant due to an impending hurricane. ${ }^{1}$ Excess emissions events are common and can result in large amounts of pollutant releases. On an average day in Texas there is one excess emissions event that releases at least 10 tons of a criteria pollutant. A recent EPA report identified natural gas gathering operations across the country as point sources that systematically release large amounts of excess emissions that often go undetected by state regulators (Environmental Protection Agency 2019a). However, despite the frequency and size of these events, excess emissions have been under-studied by environmental economists and other social scientists, are not generally reported in the national media, and are under-regulated at both the state and federal level. There are also no past studies of the health effects specifically attributable to excess emissions, which is our focus here.

\footnotetext{
${ }^{1}$ Permitted levels for various pollutants are set by state environmental agencies in order to ensure that industrial point sources of pollution do not cause or contribute to violations of the National Ambient Air Quality Standards. Permitted levels are stack and pollutant specific and are usually expressed in pounds of pollutant releases per hour. As a result, each facility can have multiple permitted levels (since each stack releases multiple pollutants) for each of its stacks.
} 
This study falls within a broader literature in economics that has, over several decades, investigated the relationship between pollution and health outcomes. A focus of that literature has been on reducing factors that could bias the estimated dose-response function-the function describing how changes in ambient concentrations of pollutants are associated with increases of mortality or morbidity. Examples of such sources of bias include avoidance (Moretti and Neidell 2011), residential sorting (Graff Zivin and Neidell 2013), omitted variable bias (Deryugina et al. 2019), endogenous policy adoption (Hollingsworth and Rudik 2019), measurement error (Aizer et al. 2018), and the challenge of separately identifying the effects of individual pollutants (Hollingsworth and Rudik Forthcoming). An identification strategy employed some work relies on large exogenous pollution shocks. For example, several papers have examined infant health impacts due to changes in maternal pollution exposure attributed to openings and closures of industrial facilities releasing toxic pollutants (Currie et al. 2015), short-term refinery closures (Lavaine and Neidell 2017), and coal-fired power plant closures (Muzhe and Shin-Yi 2018). Additional examples include Ransom and Pope III (1995), who examine hospital admissions and mortality impacts of a temporary closure of a steel mill in Utah and Hanna and Oliva (2015) who consider the labor outcomes of a refinery closure in Mexico City. Outside the economics, there is a long history of epidemiology research that studies the negative health impacts of pollutants such as ozone, particulate matter, nitrogen dioxide and sulfur dioxide (Dockery et al. 1993, Pope III et al. 2002, Klemm and Mason 2003, Jerrett et al. 2009, Smith, Xu and Switzer 2009, Lepeule et al. 2012, Di et al. 2017).

The pollution shocks we study in this paper are large-scale releases from industrial facilities due to mostly unplanned start-ups, showdowns, and malfunctions. In this sense, excess emissions are similar to changes in pollution that result from exogenous plant openings and closures since the changes are unexpected and of a similar magnitude. Thus we expect that our results will be similar in both sign and magnitude of excess emissions events on pollution and health outcomes with the results of prior studies examining openings and closings.

Our paper is the first to directly connect excess emissions with adverse changes in ambient air quality and mortality. We do so through the analysis of a rich dataset of daily excess emissions events from industrial facilities in Texas from 2002 to 2017. We take a two step approach in our analysis. First, we establish a link between excess emissions and increases in nearby ozone concentrations. Unlike previous work that simulates the pollution concentration effects of excess emissions using atmospheric plume/simulation models, our approach uses historic, observational data to show that excess emissions cause increases in actual ozone concentrations measured at air quality monitoring sites across Texas. The second step in our analysis is to estimate the effects of excess emission events on adverse health outcomes, by linking these events to increases in nearby elderly mortality. We show robust evidence that excess emissions cause an increase in all-cause elderly mortality. Consistent with prior literature, we find no clear effect on mortality until age 65. 
We then take another methodological approach that directly links pollution concentrations and mortality in an instrumental variable framework using excess emissions releases as instruments for ozone concentrations. The instruments operate in the expected direction and are well-powered. The IV results clearly demonstrate that excess emissions events lead to increased elderly mortality through increased ozone concentrations. Our instrumental variable results demonstrate that excess emissions events lead to increases in harmful ozone concentrations and that this increased pollution causes increases in elderly mortality. We show that excess emissions cause, on average, 35 elderly deaths per year in Texas. Using an integrated assessment model we estimate average total damages (inclusive of mortality, morbidity, and other damages) of at least \$74 million per year.

Our work provides two contributions to the literature. First, we demonstrate the severity of the impact of excess emissions on ambient air quality and mortality. Our study is the first to identify the environmental and health effects of this particular category of industrial releases, which has so far been relatively unexplored by environmental economists. This contribution is particularly salient in light of the recent regulatory conflict on how excess emissions regulations should be enforced. ${ }^{2}$ Second, we contribute to the small and growing literature demonstrating that pollution affects elderly mortality using a quasi-experimental research design. While a number of previous studies have shown associations between pollution and non-infant mortality (e.g., Pope et al. (2019), Gouveia and Fletcher (2000) and Pope III et al. (2002)), only a few recent studies have shown effects using a quasi-experimental research design (Deryugina et al. 2019, Deryugina and Reif 2020, Anderson 2020, Chay, Dobkin and Greenstone 2003, Chen et al. 2013, Hollingsworth and Rudik Forthcoming). We contribute to this literature by providing clear estimates of how increased ozone concentrations affect elderly mortality. We focus on eldrerly mortality as the most severe of health events amongst the most vulnerable population group. Our choice is driven by associational evidence in the literature that the elderly are more likely to have a larger relative change in the probability of mortality conditional on exposure to pollution (Gouveia and Fletcher 2000). In addition, two thirds of all mortality cases in the US occur in age groups 65 years and older (Di et al. 2017) leaving limited scope to find mortality effects in the non-elderly. Using excess emissions as an instrument for mean ozone concentrations we find that a $10 \%$ change in monthly average ozone increases elderly mortality by $3.9 \%$. We also find that this increase is driven by deaths of those aged over 85 who see a $5.2 \%$ change in mortality.

The remainder of the paper is organized as follows. Section 1 provides relevant regulatory background on excess emissions and reviews the extant literature in environmental and social sciences. We then provide a description of the data used in our analysis in Section 2. Section 3 conducts an overview of the methodology used in the paper, including reduced form, event study, and instrumental variables specifications. Section 4 presents results and Section 5 concludes.

\footnotetext{
${ }^{2}$ More detail on the regulatory framework of excess emissions is provided in section 2.
} 


\section{Regulatory Background}

Excess emissions are often attributed to unexpected or unavoidable circumstances, and thus can be difficult to manage. This is especially true if the root cause of an excess emission event is beyond the control of a facility, such as the shut-down of a plant before an impending natural disaster. However, excess emissions can also occur due to human error or poor maintenance. The distinction between truly unavoidable events and those that could have been avoided poses a heavy regulatory burden on state environmental agencies. As an administrative shortcut, state agencies for decades have relied on provisions in their State Implementation Plans (SIPs), the plans detailing how each state will maintain compliance with the Clean Air Act, to both automatically exempt many excess emissions events from being considered violations of the Clean Air Act and to allow facilities to claim affirmative defense provisions that shield them from civil lawsuits (Environmental Protection Agency 2015). These exemptions eased the enforcement burden on facilities by allowing them to request relief from penalties.

Excess emissions are technically violations of the Clean Air Act, but, historically, they have generally not been treated this way by the EPA and state agencies. While, the EPA has been aware of this issue since 1977, it was not until 2013 that the agency called for states to "remove impermissible provisions from their SIPs and to adopt other, approvable approaches for addressing excess emissions" (Environmental Protection Agency 2015). This call to remove "impermissible provisions" from state SIPs specifically targeted the affirmative defense and automatic exemption provisions discussed above.

The discrepancies around how excess emissions are treated from a regulatory perspective in SIPs, first came to light in 2011 when the Sierra Club filed a petition arguing that several states included language in their SIPs that was not in accordance with the Clean Air Act (Sierra Club 2011). Responding to the petition, the EPA released a final SIP call in 2015 (originally proposed in 2013) suggesting that 36 states had provisions in their SIPs that were "substantially inadequate to meet CAA requirements" (Environmental Protection Agency 2015) with regards to how excess emissions were treated. Those states were asked to submit updated SIPs that would bring the way excess emissions were regulated in accordance with the Clean Air Act. The 2015 SIP Call was challenged in the courts shortly after it was finalized and was held in abeyance since 2017 (Environmental Protection Agency 2019b). More recently, EPA's Region 6 and Region 4 offices finalized rules that withdraw the 2015 SIP Call findings for Texas (Region 6 office) and North Carolina (Region 4 Office) (Environmental Protection Agency 2020c;b). Based on the Region 6 rule, the Texas Commission on Environmental Quality (TCEQ) can once again include affirmative defense provisions in it's SIP (Environmental Protection Agency 2020c). In a similar deregulatory move, the EPA Region 4 rule will allow North Carolina to continue issuing automatic exemptions 
(Environmental Protection Agency 2020b) for excess emissions events. In October 2020, the EPA released a guidance memorandum to all Regional Offices, that further weakened the regulatory framework this time on a national level (Environmental Protection Agency 2020a) by allowing automatic exemptions and affirmative defense provisions to be implemented in SIPs of all states. This guidance is predicated on the concept of cooperative federalism according to which states should be afforded flexibility in their efforts to achieve and maintain compliance with the National Ambient Air Quality Standards (NAAQS), but in practice may allow state agencies to exempt excess emissions from traditional enforcement ${ }^{3}$.

Estimating the costs associated with excess emissions is important so that an effective regulatory framework can be designed. Yet, estimating these costs is challenging since little is known about the incidence and magnitude of excess emissions. Moreover, their impacts are poorly understood. The lack of research is in part due to a lack of available data; Texas is the only state that makes excess emissions data publicly available in a systematic way that is usable for research within a short time-period following an event. It is therefore no coincidence that all studies that have examined the occurrence and impacts of excess emissions have focused on Texas. ${ }^{4}$

Using these data, a small number of papers in atmospheric science have studied the incidence and frequency of excess emissions in Texas. These studies have used either atmospheric plume models or case studies of specific emissions events to demonstrate the potential impact of excess emissions on ambient air quality. Collectively, these studies document that excess emissions are frequent, large in magnitude, last from a few hours to several days (or even weeks) and can exceed a facility's routine annual emissions (Murphy and Allen 2005, Nam et al. 2006, Choi, Hyde and Fernando 2006, Kulkarni, Chellam and Fraser 2007, Vizuete et al. 2008, McCoy, Fishbeck and Gerard 2010).

No study has, to our knowledge, examined the environmental impacts of excess emissions using observational air quality data from EPA pollution monitors. In addition, no prior work has used observed mortality data to identify the impact of excess emissions on premature mortality. The closest previous paper is Zirogiannis, Hollingsworth and Konisky (2018), who use an integrated assessment model to estimate health damages from excess emissions, but do not directly link emissions and mortality.

Only three prior studies in the social sciences have examined the incidence and magnitude of excess emissions in Texas. Ozymy and Jarrell (2011) documented excess emissions from 18

\footnotetext{
${ }^{3} \mathrm{~A}$ more detailed analysis of the regulatory background regarding excess emissions is provided in Zirogiannis, Hollingsworth and Konisky (2018)

${ }^{4}$ While several states require facilities to report data on excess emissions, the information is made available to the public only on a facility-by-facility basis. Louisiana, Oklahoma and Texas maintain comprehensive datasets that allow annual excess emissions data on multiple facilities to be retrieved by a single query. In addition, Texas is the only state that makes daily-level information on excess emissions events publicly available almost in real time. More information on Texas's reporting requirements for excess emissions events is provided in Section 2.
} 
oil refineries from 2003 to 2008 and find that each refinery, on average, experienced 351 excess emissions events per year. Ozymy and Jarrell (2011) also compare excess emissions releases to emissions reported by the same refineries to the Toxics Release Inventory (TRI). They find that, in a small number of cases, pollutant releases due to excess emissions events are higher than the releases of the same pollutants reported to the TRI. Zirogiannis, Hollingsworth and Konisky (2018) detailed excess emissions from all industrial sources in Texas from 2002 to 2017. While the authors do not directly study the health effects of excess emissions, they do provide preliminary damage estimates from an integrated assessment model (Heo 2015, Heo, Adams and Gao 2016). Li, Konisky and Zirogiannis (2019) study the racial, ethnic and income disparities of excess emissions in Texas at the facility and census track level. They find that median income and percentage of Black population are positively associated with the incidence of excess emissions.

\section{Data}

To conduct our analysis, we require data on excess emissions, ozone concentrations, weather, and mortality. In this section, we discuss each in turn.

\subsection{Excess emissions data:}

The main data used in this paper come from the Texas Commission on Environmental Quality (TCEQ). Industrial facilities in Texas have been required to report total annual amounts of excess emissions to the TCEQ's Emissions Inventory (EI) since 1990. Texas House Bill 2912, which came into effect in late 2001, established the requirement that all industrial facilities report excess emissions within 24 hours to the state's Air Emissions and Maintenance Events (AEME) dataset (Texas House of Representatives 2001). 5,6

To comply with these regulations, facilities provide a preliminary disclosure in the form of an initial report to the TCEQ for each excess emissions event within 24 hours of its occurrence. After

\footnotetext{
${ }^{5}$ Due to the difference in the timing of the reporting requirement there are often non-trivial discrepancies between the amounts of excess emissions reported in the EI and AEME datasets. Zirogiannis, Hollingsworth and Konisky (2018) provide a detailed discussion regarding these discrepancies. In this paper, we only use data from the AEME dataset.

${ }^{6}$ The TCEQ does not use the term "excess emissions events" as part of the Texas Administrative Code (TAC). Instead the agency uses the term "emissions events", to define "any upset event or unscheduled maintenance, startup, or shutdown activity, from a common cause that results in unauthorized emissions of air contaminants from one or more emissions points at a regulated entity". Exceedances of a facility's permitted level can also occur during scheduled start-up, maintenance or shutdown (SSMS) events. If emissions exceed a facility's permitted level during an SSMS event, then that event is characterized as an "emissions event" by the TCEQ. Throughout the paper we will use the term "excess emissions" to denote emissions that exceed a facility's permitted level either due to a scheduled or an unscheduled start-up, shutdown or maintenance event. More details on the exact definitions of each of those terms in the TAC are provided in the Appendix.
} 
submission of the initial report, the TCEQ publicly posts details regarding the emissions event, including information on the likely type and estimated quantity of pollution released. ${ }^{7}$ Each initial report contains facility-level information (name, location, id number, etc.), information on the pollutants released (contaminant name, amount and duration of the release, beginning and ending time of the release) as well as an explanation of why the release occurred and what action was taken to minimize the release or fix the problem that caused it (Texas Commission on Environmental Quality 2016). In addition, facilities are required to state the pollutant permit limit (usually expressed in pounds per hour) from the stack or source that released each pollutant. Because events are self reported before they are fully investigated, some reported events may not have in reality exceed the permitted limit. These events are later revised downward to reflect the new information. After the emissions event has ended, the facility has two weeks to submit a final report, where it can provide the updated information regarding both the specific pollutants and the amounts released.

In the event that a final report is not filed, then the initial report becomes the de facto final report. In a majority of cases a final report is submitted that corrects for an overestimate of pollution releases in the initial report. Recall that excess emissions are those events that occur during malfunctions as well as during start-ups, shut-downs or maintenance that are above a facility's permitted levels of emissions. Therefore emissions events (or portions of the events) can occur at rates below permitted levels that are neither violations nor "excess emissions." Due to the downward revisions that often occur from an initial to a final report, the AEME dataset often contains excess emissions reports from events that are eventually found to have not released pollutants at a rate over the permitted threshold and are therefore not excess emissions.

To ensure that this idiosyncratic reporting feature does not impact our results, we perform our analysis using two datasets: 1) a "full dataset" that includes all emissions events (scheduled or unplanned) documented in the final report (regardless of whether or not the emissions exceed the permitted threshold); and 2) a "censored dataset" that includes only the portion of emissions documented in the final report that are above the permitted threshold. The reason for this distinction is twofold.

First, from a health perspective it does not matter whether an emissions event surpasses a permitted threshold. What should matter is the overall effect the event has on air quality and subsequent health outcomes. These effects are unlikely to have discontinuities at permitted thresholds. For example, suppose that facility A emits $1,000 \mathrm{lbs}$ of $\mathrm{SO}_{2}$ over a one hour period, with a permitted limit of $300 \mathrm{lbs}$ per hour. The "full dataset" would consider the entire 1,000 lbs released as the excess emissions from that event, while the "censored dataset" would only consider 700 lbs (i.e. the amount over the permitted limit).

\footnotetext{
${ }^{7}$ http://www2.tceq. texas.gov/oce/eer/
} 
Second, from a regulatory and enforcement perspective, the difference between the two outcomes is important; one could trigger a violation of the Clean Air Act, while the other is not considered a violation. As we discuss in Section 4, the main findings of our work are not affected by the choice between the two datasets, indicating that the majority of the increased pollution and associated health damages come from excess emissions events that exceed the permitted limit. ${ }^{8}$ We therefore present results using the "censored" dataset in the paper and show results using the "full" dataset in the Appendix only. This is consistent with findings in earlier work showing that the majority of excess emissions releases come from the largest events (Zirogiannis, Hollingsworth and Konisky 2018).

Table 1 provides information on the number of excess emissions events by event and report type. The censored dataset contains information on 45,231 events from 2002 to 2017(Q1); 83\% of events are unplanned emissions events and $17 \%$ are related to scheduled maintenance, start-up or shutdown (SMSS). ${ }^{9}$ Using the censored dataset, Figure 1 shows the number of facilities reporting to the TCEQ's AEME dataset every year as well as the annual count of excess emissions events recorded. In an average year there are around 465 facilities reporting over 2,900 excess emissions events. $^{10}$

\subsection{Weather data:}

Information on weather comes from the National Oceanic and Atmospheric Administration's (NOAA) NCEP-NCAR Reanalysis 1 model. This model provides daily weather data in $2.5^{\circ}$ latitude by $2.5^{\circ}$ longitude cells that cover the entire globe (Kalnay et al. 1996). ${ }^{11}$ Daily weather at each pollution monitor-day is extracted from the $2.5^{\circ}$ latitude by $2.5^{\circ}$ longitude grid cell in which each pollution monitor is located. For each cell we obtain data on average air temperature $\left(\mathrm{C}^{\circ}\right)$, pressure $(\mathrm{kPA})$, relative humidity $(\%)$, wind speed $\left(\frac{\mathrm{m}}{\mathrm{s}}\right)$, and daily precipitable water $\left(\frac{\mathrm{kg}}{\mathrm{m}^{2}}\right) .{ }^{12}$ A list of hurricanes making landfall and the dates of impact were provided by the NOAA Hurricane research division. $^{13}$

\footnotetext{
${ }^{8}$ As discussed earlier in this section, due to the downward revisions that often occur between an initial and a final report, some excess emissions events do not exceed the permitted threshold.

${ }^{9}$ An analogous table with the descriptive statistics of the full dataset can be found in the Appendix Table A1.

${ }^{10}$ Figure A1 in the Appendix reports the annual count of excess emissions events and reporting facilities for the full dataset.

${ }^{11} \mathrm{https} / / /$ www.esrl.noaa.gov/psd/data/ gridded/data.ncep.reanalysis.html

${ }^{12}$ All variables reported are surface level except for daily precipitable water, which is the total water in the atmospheric column.

${ }^{13}$ The list can be found at http://www.aoml.noaa.gov/hrd/tcfaq/E23.html and the landfall start dates can be found at https://coast.noaa.gov/hurricanes/
} 


\subsection{Mortality data:}

In our mortality analysis, we consider the death rate per 100,000 population in each county-yearmonth by cause. Underlying mortality micro-data come from the Centers for Disease Control and Prevention Multiple Cause of Death (MCOD) files for 2002-2017. The MCOD provide information on the month and year of death; county of decedent residence; basic decedent demographic information including age, race, and gender; and the underlying cause of death with up to twenty contributing causes. ${ }^{14}$ Each cause of death is reported using an International Classification of Diseases, Tenth Revision (ICD-10) code as well as by an aggregated 113 cause of death code. ${ }^{15}$ We extract a count of death by each cause in each county and month for all deaths where the decedent was above the age of 65 . We combine mortality data with county-year-age population data to calculate the county-month-year death rate by cause per 100,000 population for those aged 65+, 65-74, 75-84, and 85+. Population data come from the Surveillance, Epidemiology, and End Results (SEER) program, which is supported by the National Cancer Institute. SEER data report population estimates at the county-year-race-single year of age level. Mortality rates are age-standardized to the U.S. population.

\subsection{Pollution Data:}

We obtained daily ozone $\left(\mathrm{O}_{3}\right)$ concentration data from the EPA in pre-generated daily files. When in operation each monitor reports the hourly average ozone concentration consistent with the National Ambient Air Quality Standard (NAAQS). The federal NAAQS for ozone is 70 parts per billion ( $\mathrm{ppb}$ ) over an eight-hour time period and for any given day our data report the average onehour ozone reading. ${ }^{16}$ In addition to pollution data, information regarding each monitor's physical location (i.e. latitude and longitude) is provided. We use these location data to determine the set of excess emissions events that occur near each pollution monitor as outlined in Section 3.

\subsection{Descriptive Statistics}

Table 2 reports summary statistics for the variables of interest that will be used in our empirical analysis related to air pollution and mortality. ${ }^{17}$ The first row of Table 2 shows data on ozone concentrations at the monitor-day level. The mean ozone concentration is well below the NAAQS

\footnotetext{
${ }^{14}$ The month and year of each death are the finest temporal granularity reported.

${ }^{15}$ In addition to obtaining information on all-cause mortality, we use the aggregated recode to extract deaths related to cardiovascular (codes 53-75) and respiratory (76-89) mortality, https://www.cdc.gov/nchs/data/ datalinkage/underlying_and_multiple_cause_of_death_codes.pdf, which we examine in the Appendix.

${ }^{16}$ In order to remain in compliance with the ozone NAAQS standard, a county's annual forth highest daily value (averaged over 3 years) cannot exceed 70ppb.

${ }^{17}$ Table A3 in the Appendix provides additional descriptive statistics for variables that are used in robustness checks.
} 
threshold, with the maximum observations exceeding the NAAQS. The table also reports information on daily excess emissions releases from all industrial sources within 15 miles of a monitor. The descriptive statistics depict the heavily skewed nature of excess emissions releases. For most pollutants the mean release is just above zero tons. However, at the extreme, cumulative CO emissions within the 15 mile distance bin can reach upwards of 462 tons in a single day. The bottom two panels of Table 2 display summary statistics for the variables used in our mortality analysis: all cause mortality, measured as the death rate per 100,000 of a population in a given county, year, and month.

\section{Methodology}

\subsection{Air Pollution}

The first part of our analysis examines how release of precursor pollutants from excess emissions events impact ozone concentrations. Ground-level ozone is not directly emitted and is thus a secondary pollutant formed by a series of complex interactions related to both local weather (sunlight) and concentrations of primary precursor pollutants, $\mathrm{NO}_{x}$, VOCs, and $\mathrm{CO}$ (Muller and Mendelsohn $2012 b)$.

We estimate the change in the daily, $d$, ozone concentration at a given monitor, $m$, associated with nearby excess emissions releases of pollutant precursor $j \in P$ using the following fixed-effects model:

Ozone $_{m d}=\beta_{j}\left(\right.$ EE release of $j$ within $k$ miles $_{m d} \mid \sum_{i}^{P}($ EE release of $i \neq j$ within $k$ miles $\left.m d)=0\right)$

$$
+\eta X_{m d}+\delta_{m y}+\omega_{w}+\varepsilon_{m d}
$$

Our outcome of interest is the average daily ozone concentration of at monitor $m$ on a given day $d$. We consider the excess emissions from events that release only a single pollutant precursor $j$ $\left(\mathrm{NO}_{x}, \mathrm{VOCs}\right.$, or $\left.\mathrm{CO}\right)$. We do this because, excess emissions events that release multiple pollutants (eg. $\mathrm{NO}_{x}$ and VOCs and $\mathrm{CO}$ ) would not allow for a clean identification of the effect that each individual pollutant has on ozone. Table A2 in the Appendix documents the percentages of cases where only a single pollutant is released from excess emissions events.

As a robustness check we also consider, in the Appendix, two alternative versions of Equation 1 . One where ozone concentration is transformed using the inverse hyperbolic sine and another with the more common natural log of the concentration, $f(x)=\ln (x+1)$. 
We consider multiple versions of Equation 1, gradually increasing the distance of what is considered a nearby excess emissions event. We estimate specifications that increase this threshold from five to twenty-five miles in 5 mile increments-e.g. 0-5 miles, 0-10 miles. As an alternative approach, we also consider mutually exclusive five-mile distance bins that do not overlap-e.g. 0-5 miles, 5-10 miles. It is a priori unclear if releases of a precursor pollutant should have greater effect closer to the emissions point source or farther away. Excess emissions events release large quantities of pollutants often at a very high rate (lbs/hour). These two factors make it likely that the precursor pollutants are emitted in concentrations far denser than those from a stack during normal operation. It is possible that the concentrations are so dense that they prohibit necessary chemical or physical reactions that lead to the formation of secondary pollutants (Cohan et al. 2005). Moreover, excess emissions are not necessarily emitted at the stack level. Since releases induced by a malfunction could happen anywhere, including at the ground-level (for example, a chemical storage tank), we should not necessarily expect excess emissions to follow a similar pattern of atmospheric transport and deposition as routine stack emissions from a facility (Sutton, Reis and Baker 2009). It is because of the uncertainty associated with these differences in emissions rate, height, and concentration that we consider multiple distances in our analysis.

Our preferred specification also includes a vector of daily weather variables $\left(X_{m d}\right)$, monitorby-year fixed-effects $\left(\delta_{m y}\right)$, and week fixed-effects $\left(\omega_{w}\right)$. Week fixed-effects $\left(\omega_{1}\right.$ to $\left.\omega_{52}\right)$ are included to ensure we are not spuriously picking up a seasonal relationship between pollutant concentrations and excess emissions. Monitor-by-year fixed-effects are inclusive of monitor and year fixed-effects. Monitor fixed-effects account for time-invariant differences in the mean pollutant concentration faced by different monitors, which could be due to either real differences in local pollution or the strategic placement of air pollution sources (Monogan, Konisky and Woods 2017). Year fixed-effects account for any pollution shocks that are common to all monitors in a given year, such as reduced manufacturing from the great recession. Monitor-by-year fixed-effects have the added advantage of allowing for each monitor to have a unique, non-linear time trend. This is of particular importance as some monitors may be located near pollutant point sources that may experience related trends in both routine and excess emissions events. ${ }^{18}$ Standard errors are clustered at the county-level to correct for the potential that the within-county prediction error is correlated across time. As a robustness check, we consider in Figure A3 of the Appendix, two additional specifications without monitor-by-year fixed-effects. One specification includes daily weather variables, while another only controls for monitor and year fixed-effects.

\footnotetext{
${ }^{18}$ One data limitation of our approach is that we do not observe within year variation of routine emissions at the facility level. Routine emissions data are only reported as annual totals in the TCEQ Emissions Inventory. Moreover, routine data are only reported for Title $\mathrm{V}$ facilities. Therefore, even if some assumptions could be made about the seasonal variation of routine emissions to estimate sub-annual routine emissions, the resulting data product would exclude many small, non-Title $\mathrm{V}$ facilities that do not report routine emissions in the TCEQ Inventory.
} 


\subsubsection{Event study}

We also conduct an event study specification that serves as an additional test of our identifying assumption that excess emission events are responsible for the increased pollution concentrations. Specifically, we examine how the pollution concentration at monitor $m$ on day $d$ is affected by large excess emission events within five days using the following standard event study specification:

$$
\begin{aligned}
\text { Ozone concentration }_{m d} & =\beta_{<-5} \prod_{t=d-6}^{t=d-1000} 1\left(\text { EE release within } k \text { miles }_{m t}\right) \\
& +\sum_{t=d-5}^{t=d-2} \beta_{t} 1\left(\text { EE release within } k \text { miles }_{m t}\right) \\
& +\sum_{t=d}^{t=d+5} \beta_{t} 1\left(\text { EE release within } k \text { miles }_{m t}\right) \\
& +\beta_{>5} \prod_{t=d+6}^{t+1000} 1\left(\text { EE release within } k \text { miles }_{m t}\right) \\
& +\eta X_{m d}+\delta_{m y}+\omega_{w}+\varepsilon_{m d} .
\end{aligned}
$$

Here negative values of $t$ indicate that there will be an event $t$ days in the future from date $d$. Likewise positive values of $t$ indicate that an event occurred $t$ days before date $d$. To avoid collinearity, we consider releases that occur one day in the future (i.e., when $t=-1$ ) to be the reference category; all $\beta$ coefficients are interpreted as the effect of an excess emissions that occurred $t$ days ago relative to the effect the event had on pollution concentrations the day before it occurred. The values and confidence intervals of $\beta_{-5}$ to $\beta_{-2}$ are a test of our identifying assumption since the estimated coefficients should not be statistically different from the reference. That is, there should be no effect of the event before it happens. The estimated coefficients for $t=0$ to $t=5$ plot how the treatment effect estimate changes across time. We expect the largest effect to be on the day of the event and that the effect will decay as time passes and emissions dissipate.

For completeness we also estimate how events beyond five days from date $d$ affect the pollution concentration on day $d$. We estimate the average effect of all events before $\left(\beta_{<-5}\right)$ and after $\left(\beta_{>5}\right)$ the five day window. Since the days immediately surrounding the excess emissions date are likely to be the most comparable with date $d$ and the events outside the five day window are averaged together, we graphically report only the estimated effects within five days of the event. We report all coefficient estimates in Table A5 of the Appendix.

The event study controls for daily weather $\left(X_{m d}\right)$, monitor by year fixed effects $\left(\delta_{m y}\right)$, and week fixed effects $\left(\omega_{w}\right)$. Standard errors $\left(\varepsilon_{m d}\right)$ are clustered at the monitor level. 
The distribution of tons released in excess emissions events is quite skewed. $78 \%$ of excess emissions are released by the top five percent of events by size and over 3\% of events emit less than one pound. The event study framework considers only a binary outcome-denoted by an indicator variable, 1 (EE release within $k$ miles $_{m t}$ ) - and does not account for skew or differences in event size. The estimated treatment effect is therefore the effect of the average excess emissions event. It may very well be that the average excess emissions event has no discernible effect on air quality since there are so many extremely small events. As the purpose of the event study specification is to test for pre-trends and to examine how the effect decays across time, we restrict our attention to excess emissions events in the $95^{\text {th }}$ percentile of size or above, those events that are the most likely to affect air quality in a detectable manner. All other analyses in the paper include all excess emissions events, regardless of size and directly account for the amount of pollution released instead of using a binary event indicator.

\subsection{Mortality}

After showing the link between excess emissions and changes in ozone concentrations, we evaluate how excess emissions affect health using a direct measure, elderly mortality. We estimate the relationship between mortality rate in a given county $i$ in each month $m$ and year $y$ and within-county monthly releases of all ozone precursor pollutants from excess emissions using the following fixedeffects model:

$$
\begin{aligned}
\text { Mortality Rate }_{i m y}= & \beta^{V O C}(\mathrm{VOC} \mathrm{EE})_{i m y}+\beta^{N O_{x}}\left(\mathrm{NO}_{x}\right)_{i m y} \\
& +\beta^{C O}(\mathrm{CO} \mathrm{EE})_{i m y}+\delta_{i y}+\mu_{m}+\varepsilon_{i m y}
\end{aligned}
$$

Here our dependent variable is mean county-level monthly mortality rate per one-hundredthousand elderly residents. As robustness checks, we also consider models using inverse hyperbolic sine transformation and natural-log transformed mortality rate.

We include month $\left(\mu_{m}\right)$ fixed-effects to account for seasonality and mortality trends that may be common to all elderly Texans. We cluster our standard errors at the county-level and weight our regressions by the elderly population of interest in each county-year. In our preferred specification, we include county-by-year fixed-effects, $\delta_{i y}$. This controls for time-invariant (over the period of one year) unobservable county-level variables, unobservable shocks common to all counties within Texas in a given year, and all county-year specific unobservables. As a robustness check, we consider two additional specifications without county-by-year fixed-effects, whose results are presented in Figure A6 of the Appendix. We examine one specification where we use only county, year and month fixed effects and another where we use county-year specific control variables that cannot be included along with the county-by-year fixed-effects. Control variables include the 
unemployment rate, median income, $\%$ non-white, $\%$ Hispanic, $\%$ elderly, $\%$ in poverty, manufacturing employment, and tons of lead emitted from sources reporting in the TRI.

\subsection{Addressing threats to identification}

In our preferred specifications for air quality, we identify the treatment effect using a comparison of the dependent variable at each monitor or county to itself within a given year. Both the monitorand county-level are the most granular geographic units available for each respective data series (i.e. in the air quality and mortality models). The "unit"-by-year fixed-effects help guard against the possibility that our pollution (mortality) estimates are spurious estimates derived from differential trends specific to certain monitors (counties). For example, consider a plant's decision to adopt a pollution control device, such as a $\mathrm{NO}_{x}$ Flue Gas Recirculation (FGR) device, where the $\mathrm{NO}_{x}$ releases are measured at the stack, behind the FGR device. Such a device would result in lower routine $\mathrm{NO}_{x}$ emissions and could also result in lower excess emissions so long as those emissions are released from the stack with the new technology. An estimate without the monitor-by-year (county-by-year) fixed-effects may incorrectly attribute reductions in ambient ozone concentrations (mortality) to the reduced amount of $\mathrm{NO}_{x}$ related excess emissions. This estimate could overstate the true treatment effect because both reductions were in reality attributable to the new pollution control device. Ideally, the estimated effect should account for the changes in routine emissions, which also contribute to reduced pollution (mortality). We include monitor-by-year (county-by-year) fixed-effects for exactly this reason. This ensures that our treatment effect estimates are based upon within monitor-year (county-year) variation and reduces the likelihood that monitor (county) specific trends, nearby policy changes, or other similar unobservables are driving our findings.

A primary concern with our analyses is that there may be unaccounted for events that simultaneously cause air-pollution, increased mortality, and excess emissions events. That is, it is possible that an event may trigger both increased air pollution and mortality as well as increased excess emissions events. Hurricanes are a salient example. Hurricanes may increase non-excess emissions related air pollution due to a rise in automotive traffic related to evacuations. In addition, they are linked to increased mortality (Deryugina and Molitor Forthcoming) as well as increased excess emissions events (Zirogiannis, Hollingsworth and Konisky 2018). Hurricanes also can cause equipment failure or damage that can lead to excess emissions due to malfunctions. To mitigate this potential, before a hurricane makes landfall most industrial facilities in the affected area shutdown their operations to avoid storm and flooding related accidents. Once the hurricane has passed, facilities go through a period of start-up which often results in emissions that are above a facility's permitted levels. Thus, hurricanes are associated with an increased incidence of ex- 
cess emissions events. Zirogiannis, Hollingsworth and Konisky (2018) found that Hurricanes were related to $1.5 \%$ of all excess emissions events in Texas from 2002 to 2017.

To address this potential threat to our identification, our preferred specification drops all months that could potentially be affected by a major hurricane. The is a conservative choice since not all facilities in Texas will shut down if a hurricane hits the Gulf of Mexico. It is more likely that shutdowns and start-ups will affect only facilities in the landfall zone. However, we make the choice of removing all facilities in the hurricane months in the absence of a systematic way to detect which facilities close and which remain in operation. ${ }^{19}$

Recall from Section 2 that the excess emissions data can be constructed in two ways: 1) using a "full dataset" that includes all reported emissions events regardless of whether or not the emissions exceed the permitted threshold; and 2) using a "censored dataset" that includes only the portion of reported emissions that are above the permitted threshold. These two constructions, combined with the inclusion or exclusion of hurricane months, result in four datasets. Our preferred and most conservative dataset is the censored one that excludes hurricane months. The censored dataset excludes any initially reported excess emissions events that are later determined not to be excess emissions events since the emission release did not exceeded permitted levels. The exclusion of hurricane months minimizes the likelihood of omitted variable bias related to hurricanes. Results presented in Section 4 use only our preferred dataset. We present results from all other datasets in the Appendix.

We next consider an instrumental variable specification that addresses remaining endogeneity concerns.

\subsection{Instrumental variables}

Thus far we have presented two separate regression approaches on how excess emissions affect ozone concentrations and how excess emissions affect elderly mortality. Next we directly link these two specifications in a two stage least squares framework with monthly excess emissions of precursor pollutants to ozone serving as instrumental variables for monthly ozone concentrations. The instrumental variables approach has several advantages. First it addresses the possibility of measurement error in monthly ozone levels. As has been demonstrated in the literature, an instrumental variable specification can help address issues related to measurement error (Aizer et al. 2018, Deryugina et al. 2019, Keiser 2019). Second, it accounts for the possibility that an omitted variable related to increases in ozone as well as increases in elderly mortality is driving our

\footnotetext{
${ }^{19}$ The following months are considered major hurricane months and are excluded whenever noted: July 2003 (Claudette), September 2005 (Rita), July 2008 (Dolly), September 2007 (Humberto), and September 2008 (Ike).
} 
results. ${ }^{20}$ Finally, it addresses the different time scales (daily excess emissions events in the specification of section 3.1 and monthly excess emissions events in the specification in section 3.2) by using county-month measures of ozone in both the first stage (the pollution concentrations) and second stage (mortality) regressions, discussed below. This approach directly traces out how excess emission induced ozone affects elderly mortality. We estimate the following two equations:

$$
\begin{aligned}
\text { Ozone }_{i m y}= & \beta^{V O C}(\mathrm{VOC} \mathrm{EE})_{i m y}+\beta^{N O_{x}}\left(\mathrm{NO}_{x}\right)_{i m y}+\beta^{C O}(\mathrm{CO} \mathrm{EE})_{i m y} \\
& +\omega X_{i m y}+\delta_{i y}+\mu_{m}+\varepsilon_{i m y}
\end{aligned}
$$

$$
\text { Mortality rate }_{i m y}=\beta{\widehat{\mathrm{Ozone}_{i m y}}}+\omega X_{\text {imy }}+\delta_{i y}+\mu_{m}+\varepsilon_{i m y}
$$

Since the pollution and mortality data are at different temporal and geographic levels we aggregate the pollution data to the lowest common denominator, the county-month. A simple way to perform this aggregation would be to take the mean ozone reading in each county month. However, it is possible that excess emissions detectably affect daily average ozone levels in the few days following a release, but have no detectable effect on monthly averages. That is, even a large increase in a given day's ozone levels may have a limited affect on the monthly average. Therefore we conduct our analysis using multiple county-month ozone measures constructed from the daily data: the mean, the median, the $75^{\text {th }}$ percentile, the $90^{\text {th }}$ percentile, the $95^{\text {th }}$ percentile, the $99^{\text {th }}$ percentile, and the maximum daily reading.

For the first stage, we expect that the specifications using larger percentiles will be more precisely estimated and greater in magnitude for the first stage since fewer days of the month need to be affected by excess emissions to see changes in larger percentiles. However, we also expect the larger percentile specifications to have smaller and less detectable mortality effects in our second stage analysis because it may be less damaging to have a few poor days of air quality relative to worse air quality on more than half the days of the month. It is due to this trade-off that we cannot a priori determine which is our preferred measure of ozone and we choose to report results from a variety of ozone measures.

In all our two-stage least squares regressions we weight by the population of the subgroup under consideration and control for monthly average weather $\left(X_{i m y}\right)$, county-by-year fixed effects

\footnotetext{
${ }^{20}$ In our preferred specification, we drop hurricane months due to the concern that these may be associated with both excess emissions and elderly mortality. It is worthwhile to note that work by (Zou and Wu 2005) finds that ozone levels actually decrease due to hurricane activity. While this would bias us away from finding an effect, we still prefer to drop hurricane months since these months may see both increases in excess emissions as well as elderly mortality due to hurricane related effects, which would be a violation of our exclusion restriction.
} 
$\left(\delta_{i y}\right)$, and month fixed effects $\left(\mu_{m}\right)$. Standard errors $\left(\varepsilon_{i m y}\right)$ are clustered at the county level and corrected to account for the chained nature of the estimation procedure using the standard two stage least squares corrections.

A limitation of this approach is that we are limited to the set of counties that include ozone monitors. This is not a limitation in the unlinked specification (discussed in Section 3.2) that directly compares excess emissions and elderly mortality since we have data on these variables for every county-month in Texas over the time period studied. Luckily, ozone monitors are placed in the most populated counties, so despite having fewer observations, counties with monitors cover almost $70 \%$ of the elderly population. Moreover, since our regressions are weighted by elderly population it is unlikely that our treatment effect estimates are being driven by the smallest counties.

\section{Results and discussion}

\subsection{Air Pollution}

Our first set of results establishes the link between excess emissions and ozone concentrations. Our dependent variable is the daily average ozone concentration at EPA pollution enforcement monitors within Texas from 2002 to the first quarter of 2017. We evaluate Equation 1 for three different pollutants of interest, estimating the impact of $\mathrm{CO}, \mathrm{NO}_{x}$ and $\mathrm{VOC}$ excess emissions on ozone concentrations (Muller and Mendelsohn 2012b, p. 30). We consider a number of specifications, distances, datasets, and transformations of the dependent variable. Due to the large number of results, and for ease of exposition, only the results of our preferred specification are presented in full in the main text. The remaining results are discussed briefly in the main text and presented in full in the Appendix.

Table 3 presents the results of our preferred specification and most conservative dataset for a fifteen-mile distance bin where the dependent variable is average daily ozone concentration in parts per billion (ppb). ${ }^{21}$ Table 3 shows results of our preferred specification that uses monitor-by-year fixed effects and week fixed effects. A 100 ton increase in VOC, $\mathrm{CO}$ and $\mathrm{NO}_{x}$ excess emissions within fifteen miles of a given monitor is associated with a $3.7 \mathrm{ppb}, 6.6 \mathrm{ppb}$, and $66 \mathrm{ppb}$ increase in measured ozone concentrations, respectively. As a reminder the NAAQS threshold for ozone is 70ppb. Table A4 in the Appendix, provides evidence that our results are robust to different model specifications.

\footnotetext{
${ }^{21}$ We choose 15 miles since this provides the nearest approximation to the size of the median Texas county while still maintaining our five mile increment. The median Texas county has 910 square miles of land area. A radius around the monitor of 15 miles produces an area of 707 square miles. Our results are robust to other distance thresholds and are reported in the Appendix.
} 
We examine the effect of the distance between the monitor and the source of the excess emissions release in two alternative ways: 1) by drawing incrementally larger distance bins around a monitor (0-5 miles, 0-10 miles. 0-15 miles, etc.) and summing all excess emissions events within that bin and 2) by considering mutually exclusive bins of the same width (0-5 miles, 5-10 miles, 10-15 miles, etc.). These two approaches allow us to examine the importance of distance between excess emissions and air quality measured at nearby monitors.

When using the overlapping bins, as we increase the distance from each monitor, the land area considered grows quadratically. Thus both the total number and total amount of pollution releases from excess emissions events within 25 miles of a monitor may be much larger than the totals within 5 miles. The increased count and total amount of daily emission events for the largest distance specifications likely contribute to improved statistical power by reducing noise (i.e., shrinking the standard error of the regression coefficient relative to the smaller distance specifications). This is also true, but for a lesser extent, when using the mutually exclusive bins. ${ }^{22}$ Thus, while we expect that pollution releases closer to a monitor should lead to larger increases in measured ozone concentrations than farther away releases, we also expect the farthest away bins to be more precisely estimated.

We visually report the results of our preferred specification across these two sets of distance bins in Figure 2. The left panel of Figure 2 uses mutually exclusive distance bins, while the right panel uses overlapping bins. The dependent variable is the mean daily ozone concentration (in ppb) and $95 \%$ confidence intervals are displayed by the brackets behind each marker. Both sets of results are consistent with the fifteen-mile distance models presented in Table 3 showing that excess emissions of $\mathrm{NO}_{x}$, VOCs and CO cause increases in nearby ozone concentrations. Consistent with our prediction, the estimated treatment effect becomes more precisely estimated as the distance bins grow larger and this precision increases the most for the overlapping distance bin specifications.

\subsubsection{Event Study}

Figure 3 displays our event study estimates for ozone concentrations. ${ }^{23}$ There is a clear and large increase in ozone concentrations on the day of and day following a large excess emissions event. The effect dissipates by the third day, becoming indistinguishable from zero. Importantly, events in the future do not affect pollution concentrations in the past. These flat pre-trends suggest that our identification assumption is likely to be met. That is, conditional on our fixed-effects and

\footnotetext{
${ }^{22}$ The distance in the $15-20$ bin is larger (550 sq. mi.) than the 10-15 bin (392 sq. mi.).

${ }^{23} \mathrm{We}$ also explored the effect of excess emissions on particulate matter concentrations. We found a similar pattern of results indicating that excess emissions are associated with increases in particulate matter concentrations. However, event study estimates did not show clear and flat pre-trends. These results are available upon request.
} 
weather controls, in the absence of an excess emissions event there would likely be no observable difference between pollution concentrations at monitors near excess emission releasing facilities compared to concentrations at monitors far away from releasing facilities.

\subsubsection{Other robustness checks}

Figures A2 and A3 in the Appendix conduct a series of robustness checks using different datasets and specifications. The estimated relationship between excess emissions and ozone formation is remarkably stable, indicating that our results are not driven by routine emissions events that are first incorrectly classified as excess emissions events, by hurricanes, or by specification choices. Further evidence supporting the validity of our specification choice is provided in Figure A4, where we show that the release of excess emissions of pollutants that are not precursors of ozone are not related to nearby ozone formation.

\subsection{Mortality}

While the estimated relationship between excess emissions and ozone concentration is statistically significant, this does not immediately imply that the relationship is economically meaningful. Since the vast majority of events are small, it could be the case that even though excess emissions events increase nearby ozone concentration, the average event may not be large enough to affect nearby population health in a detectable manner. In this section we demonstrate the link between excess emissions releases and mortality. We then quantify, in Section 4.4, the magnitude of this effect by both using our empirical results to estimate the number of additional elderly deaths that are due to excess emissions and by using an integrated assessment model to provide an estimate of the total damages from excess emissions.

To establish the link between excess emissions and increased elderly mortality, we evaluate Equation 3 for the all-cause mortality rate for each elderly age-group. Here our data are at the county-month-year level, which represents the most granular level that the mortality data are reported. The independent variables of interest are the tons of excess emissions released in each county-month-year.

These results are presented in Figure 4 and show that excess emissions of VOCs and CO increase elderly mortality. ${ }^{24}$ The effects are driven by those aged 75 and older, with no detectable effects for those aged 65 to 74. A 100 ton increase in VOC excess emissions causes 5.4 more deaths per 100k for those above 85. Similarly, a 100 ton excess CO emissions event would cause

\footnotetext{
${ }^{24}$ The exact point estimates and standard errors are presented in Table A7.
} 
1.8 more deaths per $100 \mathrm{k}$ for those aged 75 to 84 and — an imprecisely estimated -4 more deaths per $100 \mathrm{k}$ for those above $85 .^{25}$

These findings are robust across both the choice of dataset, specification, and transformation of the dependent variable, which is demonstrated by Figures A5 and A6 in the Appendix. We find only slight differences in the estimate from the preferred model as we vary the underlying dataset or specification. Relative to using the untransformed (i.e. mean) dependent variable, when using the natural log or inverse hyperbolic sine transform our precision increases for the $\mathrm{CO}$ coefficient in the $65+$ and $75-84$ age groups. This is likely a reflection of the large number of zero valued observations in our data.

\subsection{Instrumental variables}

Results from our instrumental variable analysis are presented in Tables 4 and 5. Table 4 shows our first stage analyses: the relationship between monthly excess emissions of precursor pollutants to ozone (VOC, $\mathrm{NO}_{x}$, and $\mathrm{CO}$ ) and various measures of monthly ozone pollution. We show results for each age-category considered in the paper $(65+, 65-74,75-84$, and $85+)$. There are differences in the first stage results across age-categories only because of differences in the population variable used to weight each county month (we use the population of each respective age-group).

Different columns use different measures of monthly ozone, the first column uses average monthly ozone, while the second uses median ozone. As we move right, ozone measures are from progressively larger percentiles of the daily distribution in each month. The greater the percentile, the smaller the portion of the right tail of the distribution is considered. The most extreme is the sixth column, which is just the maximum daily average in each month.

Our first stage results show that our instrumental variables are well-powered and work in the expected direction. All F-statistics are above 28, which is well above the Kleibergen-Paap critical threshold of 9.08 for $10 \%$ bias when three instruments are used. As expected, excess emissions have the largest and most precisely estimated effects on the right tail of the distribution of daily ozone levels in each month. Thus the largest and most precise estimates are in the far right columns. In accordance with our expectations, VOC emissions are particularly effective at creating ozone, which is demonstrated by the positive and significant coefficient no matter the ozone measure used.

Table 5 presents results from our second stage. As with our first stage results, the columns index different measures of ozone. Each set of results considers the mortality rate per 100,000 population by different age groups. Each coefficient can be interpreted as the effect of a one unit change in the measure of ozone associated with that column on the elderly mortality rate of the

\footnotetext{
${ }^{25}$ In Appendix Table A6 we examine the effect by cause of death. When using the untransformed mean as the dependent variable, we find weak evidence that the all-cause mortality results are driven by cardiovascular deaths, but these coefficients are imprecisely estimated.
} 
respective age group. For example, a one unit increase in the median daily ozone reading in a month causes 26.84 (2.3\%) more deaths per 100,000 aged 85 and above. Similarly for those aged 75 to 84 a one unit increase in the median ozone causes $7.06(1.7 \%)$ more deaths per 100,000.

The largest effects are for the 85+ group, with smaller effects for the 75-84 year old group, and no discernible effect for those aged 65 to 74 . As expected the largest mortality effects are for the average and median measures of ozone and the smallest and least precisely estimated are for the ozone measures that consider more extreme outcomes. This is sensible because the different measures indicate dramatically different exposures to ozone; raising the median ozone concentration over an entire month means that the entire right half of the distribution would need to increase, raising the average could be done by having an increase on every day or very large increases on just a few days, increasing the largest percentiles need only affect a small number of days, and altering the maximum daily reading need only affect one day.

Overall we find strong evidence that ozone affects elderly mortality. Those results are more comparable when presented as elasticities. A $10 \%$ change in monthly average ozone increases elderly mortality by $3.9 \%$. This change is driven by older cohorts, where the same ozone change induces a $5.2 \%$ increase in mortality of those aged above 85 . We find similar effects using median monthly ozone concentrations. In addition to the mean and median, we also show evidence that highest ozone concentration days of the month are important. We find that a $10 \%$ increase in the $99^{\text {th }}$ percentile or the maximum monthly ozone concentration causes around a $3 \%$ increase in elderly mortality. As with the mean and median results, this is driven by those aged 75 and above.

\subsection{Interpretation of results}

While we have shown that excess emissions increase both harmful nearby pollution and elderly mortality, we have yet to quantify the magnitude of the effect. As previously discussed, our empirical estimates report the impact of 100 tons of excess emissions by pollutant. The use of 100 tons is done for ease of coefficient interpretation, but the average excess emissions event releases far less than 100 tons of any given pollutant. We show two estimates that better capture the magnitude of excess emissions damage by accounting for the size and frequency of actual excess emissions events. Using our mortality estimates, we first predict the number of premature elderly deaths that excess emissions cause in each year and estimate the associated damages. We then calculate estimated damages from excess emissions using an integrated assessment model, which quantifies marginal pollution damages from mortality, morbidity, and other sources.

Our estimates from Section 4.2 indicate that excess emissions increase all-cause elderly mortality within the same month. Combining the estimated coefficients with data on the actual frequency and size of excess emissions by pollutant allows us to predict the number of premature deaths 
caused by excess emissions in each year. Excess emissions of $\mathrm{VOCs} \mathrm{NO}_{x}$, and $\mathrm{CO}$ are associated with around 35 additional elderly deaths per year in Texas. To compare this number with the results from an existing integrated assessment model (specifically the Air Pollution Emissions Experiments and Policy (APEEP) model developed by Muller and Mendelsohn (2012a)), we must determine a dollar value for these premature deaths. To mitigate this issue, we consider the monetary value of life years lost. The average age of an adult aged 65 and above is 74.10 and conditional on reaching this age, life expectancy is 87 (Murphy et al. 2017). Thus each premature death of an adult aged 65 and older results in an average decrease of 12.9 years of life. If each life year lost is valued at $\$ 137,258.10$ in 2019 (Cutler 2004), each premature elderly death causes $\$ 1,770,629.49$ in damages. However, we need to adjust this figure to account for the possibility of "harvesting" (or "mortality displacement"), which denotes the likelihood that premature elderly deaths due to excess emissions events might have occurred (at a somewhat latter time) even in the absence of excess emissions. Using estimates derived from Deryugina et al. (2019) we adjust the value of each premature elderly death by $31 \%$ which brings our estimated value down to $\$ 548,895.14 .^{26}$ Thus in an average year in Texas the 35 additional elderly deaths caused by excess emissions are valued at over $\$ 19.3$ million. $^{27}$

We use a similar approach to estimate damages using results from our instrumental variables specifications. Using the point estimates from our multiple IV specifications, we find very similar damage estimates as we do when we use OLS. We estimate that average annual damages are (in millions) \$18.6 when using mean monthly ozone, $\$ 13.6$ when using using $75^{\text {th }}$ percentile monthly ozone, $\$ 13.8$ when using using $90^{\text {th }}$ percentile monthly ozone, $\$ 23.8$ when using using $95^{\text {th }}$ percentile monthly ozone, and $\$ 19.8$ when using using max monthly ozone.

In addition to damages estimates based on our elderly mortality analysis, we also provide damage estimates of excess emissions that use the Air Pollution Emissions Experiments and Policy (APEEP) model (Muller and Mendelsohn 2012a). We do this for two reasons. First, this provides an order of magnitude check on our elderly mortality derived damage estimates. Second, the APEEP estimate considers additional (i.e., non-elderly mortality) sources of damage that are not directly considered in our manuscript.

The APEEP model provides a deterministic and static prediction of the marginal damage per ton of pollutant emitted in a given county. The main input to the APEEP model is the amount of pollution released in each source county. The model assumes how releases of pollution affect

\footnotetext{
26 This $31 \%$ deflation of each life year lost is equivalent to assuming each decedent would have live only $31 \%$ of the average remaining life years for their age group.

${ }^{27}$ Despite our deflation of the value of each life lost, which accounts for possible harvesting, it is still possible that our estimated damages are too large. This could occur if the deaths driving the mortality estimates in the 65 and older group are from the most elderly ( 85 and above), who have fewer expected remaining life years. The average age of an individual 85 and above is 88.7 with 5.3 expected years of life remaining. If we were to use this as the basis for our damage estimate instead, it results in a $41 \%$ smaller annual damage estimate
} 
air quality in downwind receptor counties. A prediction is then provided of how these changes in air quality will affect morbidity, mortality, reduced agricultural productivity, air visibility, lost recreational days, and the depreciation of some man-made materials in receptor counties. For each outcome and in each county, the relationship between changes in a pollutant concentration and changes in each outcome is assumed, with the exact coefficient taken from prior scientific and epidemiological studies. Total damages are a monetized aggregate of changes across all outcomes.

The main benefit of using the APEEP model for damage estimates is that it considers a wider range of outcomes that are affected by pollution. A second advantage is that the APEEP model considers damages that can occur in counties downwind of the pollution-releasing county. The biggest drawback of APEEP is the assumed relationship between changes in pollution exposure and changes in health and non-health outcomes.

Conversely the primary benefit of constructing damage estimates based upon our elderly mortality analysis is better identification; the relationship is not assumed to exist, but instead is estimated using a quasi-experimental research design. However, a clear shortcoming of the elderly mortality only approach is the narrow focus; it does not account for other consequences of increased pollution and does not consider mortality that may occur in counties beyond the county that is the source of the pollution.

We expect that APEEP based damage estimates will be somewhat larger than damage estimates that only consider in-county elderly mortality. However we also expect that the elderly mortality damage estimates will compose a sizeable fraction of the total damage estimates from APEEP. Prior work has found that the majority of damages in integrated assessment models like APEEP come from changes in mortality (Environmental Protection Agency 1999a) and that for a given increase in pollution the elderly are the most likely age group to see increased mortality (Gouveia and Fletcher 2000).

It should also be noted that APEEP damages do not account for harvesting. APEEP uses the full value of statistical life in estimating premature mortality damages; this does not take into consideration the health status or age of the decedent. Because of this, uncorrected APEEP damages estimates will be too large as they will overstate life years lost due to pollution. As done with our elderly mortality based damage estimates, we correct for this overstatement by applying a $31 \%$ deflator based on Deryugina et al. (2019). It is important to note that this deflator over-corrects for the overstated life-years lost. This is the case because there is no evidence that we are aware of that shows that damages from the other outcomes (recreation days, agricultural yields, etc) included in the APEEP estimates are over-stated. Thus this correction is quite conservative as it biases the APEEP damage estimates towards zero.

Using the harvesting corrected APEEP model we find that damages are estimated to be $\$ 74$ million per year and using our elderly mortality induced excess emissions results we find that 
damages are $\$ 19.3$ million per year. Figure 5 shows all our damage estimates by year. The solid grey line represents harvesting adjusted APEEP damage estimates. The solid black line represents damages from 65+ premature mortality from excess emissions using our OLS estimates. The white dashed line represents damage estimates based on IV specifications that use mean monthly ozone as an instrumental variable. For clarity, we do not present specific damage estimates based on our other IV estimates since there is substantial overlap. However, these results are quite similar to the mean monthly ozone based results and we present the range of these estimates for any given year using the grey shaded area. ${ }^{28}$

\section{Conclusion}

This study contributes to a growing literature in economics that leverages large pollution shocks to understand environmental, health, labor, and other impacts (e.g., Ransom and Pope III 1995, Hanna and Oliva 2015, Currie et al. 2015, Lavaine and Neidell 2017, Muzhe and Shin-Yi 2018). Here, we clearly demonstrate that excess emissions in Texas are associated with both impaired air quality and premature elderly mortality. These findings are robust across a number of different model specifications, including models that we believe are conservative in their assumptions. According to our estimates, excess emissions of VOCs and CO alone account for an average of 35 additional elderly deaths per year in Texas. In addition, monetary damages from mortality, morbidity, and other sources, attributed to excess emissions reach \$74 million (in 2019 \$) a year.

Given the magnitude of these estimates, our analysis further shows that excess emissions are an important category of air pollution releases that deserve broader attention. Unlike temporary pollution shocks associated with plant openings or closures, excess emissions occur regularly and at currently operating plants. Future work should investigate other important implications, including the relationship between excess emissions and other well-known adverse health outcomes associated with poor air quality. Of particular interest should be respiratory morbidity such as asthma, especially among sensitive populations such as children, as well as low birth weight and infant mortality. Future analysis should also aim to improve on the temporal resolution of our study. Although the data on excess emissions available from the state of Texas are measured on a daily

\footnotetext{
${ }^{28}$ In previous work Zirogiannis, Hollingsworth and Konisky (2018) estimate that excess emissions cause approximately $\$ 150$ million in mortality damages per year in Texas. This number differs from those above for two reasons. First Zirogiannis, Hollingsworth and Konisky (2018) use the EASUIR integrated assessment model developed by Heo (2015) to estimate annual mortality damages rather than APEEP or an empirical approach like the one in this manuscript. EASUIR differs from APEEP in that it does not estimate damages from morbidity, agriculture, recreation, and depreciation of man made goods. Second Zirogiannis, Hollingsworth and Konisky (2018) do not adjust the EASUIR estimates to account for harvesting using the correction based on Deryugina et al. (2019). After applying the simple $31 \%$ deflator to the $\$ 150$ million estimate from Zirogiannis, Hollingsworth and Konisky (2018), the damage estimate becomes $\$ 46.5$ million, which is comparable to those presented in this text.
} 
level, mortality data from the Center for Disease Control and Prevention are monthly. This temporal mismatch may obscure the effects of emissions on health outcomes, which highlights the potential dividends of employing daily or weekly health outcomes to better identify adverse health impacts.

Further research into the incidence and effects of excess emissions is critical given the ongoing policy uncertainty around these emissions. Although the EPA has unequivocally stated that excess emissions are violations of the Clean Air Act, as a matter of policy the agency has largely chosen to neglect them. For this reason, excess emissions historically have been under-regulated. Only since 2015 did the EPA begin to insist that state environmental agencies revise the policies encoded in their SIPs. Over the last few years, the EPA has demonstrated a shift towards a deregulatory agenda on excess emissions, predicated on an interpretation of the Clean Air Act's core principle of cooperative federalism, according to which states should have latitude in how they meet federal air quality rules. This deregulatory agenda, is certain to create controversy, and likely reignite a legal response from environmental advocacy organizations. In fact, in January 2021, the Biden Administration, announced that it would re-examine the 2020 EPA memorandum that allows affirmative defense provisions and automatic exemptions in SIPs. Further research on excess emissions can inform this debate by providing a more robust explanation of the implications of any decision to change the relevant regulatory framework. 


\section{References}

Aizer, Anna, Janet Currie, Peter Simon and Patrick Vivier. 2018. "Do Low Levels of Blood Lead Reduce Children's Future Test Scores?" American Economic Journal: Applied Economics 10(1):307-341.

Anderson, Michael L. 2020. "As the Wind Blows: The Effects of Long-Term Exposure to Air Pollution on Mortality." Journal of the European Economic Association 18(4):1886-1927.

Brooks, Nancy and Rajiv Sethi. 1997. "The Distribution of Pollution: Community Characteristics and Exposure to Air Toxics." Journal of Environmental Economics and Management 32(2):233250.

Chay, Kenneth, Carlos Dobkin and Michael Greenstone. 2003. "The Clean Air Act of 1970 and Adult Mortality." Journal of Risk and Uncertainty 27(3):279-300.

Chen, Y., A. Ebenstein, M. Greenstone and H. Li. 2013. "Evidence on the Impact of Sustained Exposure to Air Pollution on Life Expectancy from China's Huai River Policy." Proceedings of the National Academy of Sciences 110(32):12936-12941.

Choi, Yu-Jin, Peter Hyde and HJS Fernando. 2006. "Modeling of episodic particulate matter events using a 3-D air quality model with fine grid: Applications to a pair of cities in the US/Mexico border." Atmospheric Environment 40(27):5181-5201.

Cohan, Daniel S., Amir Hakami, Yongtao Hu and Armistead G. Russell. 2005. "Nonlinear Response of Ozone to Emissions: Source Apportionment and Sensitivity Analysis." Environmental Science \& Technology 39(17):6739-6748.

URL: https://pubs.acs.org/doi/10.1021/es048664m

Colmer, Jonathan, Ian Hardman, Jay Shimshack and John Voorheis. 2020. "Disparities in PM2. 5 air pollution in the United States.' Science 369(6503):575-578.

Currie, Janet, John Voorheis and Reed Walker. 2020. What caused racial disparities in particulate exposure to fall? New evidence from the Clean Air Act and satellite-based measures of air quality. Technical report National Bureau of Economic Research.

Currie, Janet, Lucas Davis, Michael Greenstone and Reed Walker. 2015. "Environmental health risks and housing values: evidence from 1,600 toxic plant openings and closings." American Economic Review 105(2):678-709.

Cutler, David M. 2004. Your Money or Your Life: Strong Medicine for America's Health Care System. New York, New York: Oxford University Press.

URL: http://www.amazon.com/Your-Money-Life-Medicine-Americas/dp/0195181328

Deryugina, Tatyana and David Molitor. Forthcoming. "Does When You Die Depend on Where You Live? Evidence from Hurricane Katrina." American Economic Review .

Deryugina, Tatyana, Garth Heutel, Nolan H Miller, David Molitor and Julian Reif. 2019. "The mortality and medical costs of air pollution: Evidence from changes in wind direction." American Economic Review 109(12):4178-4219.

Deryugina, Tatyana and Julian Reif. 2020. "Pollution and Mortality in the United States: Evidence from 1972-2015.”.

Di, Qian, Yan Wang, Antonella Zanobetti, Yun Wang, Petros Koutrakis, Christine Choirat, Francesca Dominici and Joel D Schwartz. 2017. "Air pollution and mortality in the Medicare population.” New England Journal of Medicine 376(26):2513-2522.

Dockery, Douglas W, C Arden Pope, Xiping Xu, John D Spengler, James H Ware, Martha E Fay, Benjamin G Ferris Jr and Frank E Speizer. 1993. "An association between air pollution and mortality in six US cities." New England Journal of Medicine 329(24):1753-1759.

Environmental Protection Agency. 1997. The Benefits and Costs of the Clean Air Act, 1970 to 1990. Technical report Environmental Protection Agency 1200 Pennsylvania Avenue, N.W., Washington, D.C.: .

Environmental Protection Agency. 1999a. The Benefits and Costs of the Clean Air Act 1990 to 2010. Technical Report EPA-410-R-99-001.

Environmental Protection Agency. 1999b. The Benefits and Costs of the Clean Air Act, 1990 to 2010 - First Prospective Study. Technical Report EPA-410-R-99-001 Environmental Protection Agency 1200 Pennsylvania Avenue, N.W., Washington, D.C.: .

Environmental Protection Agency. 2015. "State Implementation Plans: Response to Petition for Rulemaking; Restatement and Update of EPA's SSM Policy Applicable to SIPs; Findings of 
Substantial Inadequacy; and SIP Calls To Amend Provisions Applying to Excess Emissions During Periods of Startup, Shutdown and Malfunction; Final Rule.".

Environmental Protection Agency. 2017. “Our Nation's Air.”.

Environmental Protection Agency. 2019a. EPA Observes Air Emissions from Natural Gas Gathering Operations in Violation of the Clean Air Act. Enforcement Alert EPA 325-F-19-001 Office of Enforcement and Compliance Assurance.

Environmental Protection Agency. 2019b. "Withdrawal of Finding of Substantial Inadequacy of Implementation Plan and of Call for Texas State Implementation Plan Revision- Affirmative Defense Provisions.".

Environmental Protection Agency. 2020a. "Inclusion of Provisions Governing Periods of Startup, Shutdown, and Malfunctions in State Implementation Plans.".

Environmental Protection Agency. 2020b. "SIP Call Withdrawal and Air Plan Approval; NC: Large Internal Combustion Engines $\mathrm{NO}_{x}$ Rule Changes.".

Environmental Protection Agency. 2020c. "Withdrawal of Finding of Substantial Inadequacy of Implementation Plan and of Call for Texas State Implementation Plan Revision- Affirmative Defense Provisions.".

Gouveia, Nelson and Tony Fletcher. 2000. "Time Series Analysis of Air Pollution and Mortality: Effects by Cause, Age and Socioeconomic Status." Journal of Epidemiology \& Community Health 54(10):750-755.

Graff Zivin, Joshua and Matthew Neidell. 2013. "Environment, Health, and Human Capital." Journal of Economic Literature 51(3):689-730.

Hand, J L, B A Schichtel, W C Malm and M L Pitchford. 2012. "Particulate sulfate ion concentration and SO2 emission trends in the United States from the early 1990s through 2010." Atmospheric Chemistry and Physics 12:10353-10365.

Hanna, Rema and Paulina Oliva. 2015. "The effect of pollution on labor supply: Evidence from a natural experiment in Mexico City." Journal of Public Economics 122:68-79.

Heo, Jinhyok. 2015. "Evaluation of Air Quality Impacts on Society: Methods and Application.". URL: http://repository.cmu.edu/dissertations/503

Heo, Jinhyok, Peter J Adams and H Oliver Gao. 2016. "Public health costs of primary PM2. 5 and inorganic PM2. 5 precursor emissions in the United States." Environmental Science \& Technology 50(11):6061-6070.

Hollingsworth, Alex and Ivan Rudik. 2019. "External Impacts of Local Energy Policy: The Case of Renewable Portfolio Standards." Journal of the Association of Environmental and Resource Economists 6(1):187-213.

Hollingsworth, Alex and Ivan Rudik. Forthcoming. "The Effect of Leaded Gasoline on Elderly Mortality: Evidence from Regulatory Exemptions." American Economic Journal: Economic Policy.

Jerrett, Michael, Richard T Burnett, C Arden Pope III, Kazuhiko Ito, George Thurston, Daniel Krewski, Yuanli Shi, Eugenia Calle and Michael Thun. 2009. "Long-term ozone exposure and mortality." New England Journal of Medicine 360(11):1085-1095.

Kalnay, E, M Kanamitsu, R Kistler, W Collins, D Deaven, L Gandin, M. Iredell, S. Saha, G. White, J. Woollen, Y. Zhu, A. Leetmaa, R. Reynolds, M. Chelliah, W. Ebisuzaki, W. Higgins, J. Janowiak, K. C. Mo, C. Ropelewski, J. Wang, Roy Jenne and Dennis Joseph. 1996. "The NCEP/NCAR 40-Year Reanalysis Project." Bulletin of the American Meteorological Society 77(3):437-471.

URL: https://doi.org/10.1175/1520-0477(1996)077\%3C0437:TNYRP\%3E2.0.CO;2

Keiser, David A. 2019. "The missing benefits of clean water and the role of mismeasured pollution." Journal of the Association of Environmental and Resource Economists 6(4):669-707.

Klemm, R J and R Mason. 2003. "Replication of reanalysis of Harvard Six-City mortality study." Revised analyses of time-series studies of air pollution and health. Special report. Boston, MA: Health Effects Institute 165.

Kulkarni, Pranav, Shankararaman Chellam and Matthew P Fraser. 2007. "Tracking petroleum refinery emission events using lanthanum and lanthanides as elemental markers for PM2. 5." Environmental Science \& Technology 41(19):6748-6754. 
Lavaine, Emmanuelle and Matthew Neidell. 2017. "Energy production and health externalities: Evidence from oil refinery strikes in france." Journal of the Association of Environmental and Resource Economists 4(2):447-477.

Lepeule, Johanna, Francine Laden, Douglas Dockery and Joel Schwartz. 2012. "Chronic exposure to fine particles and mortality: an extended follow-up of the Harvard Six Cities study from 1974 to 2009." Environmental Health Perspectives 120(7):965-970.

Li, Zhengyan, David M Konisky and Nikolaos Zirogiannis. 2019. "Racial, ethnic, and income disparities in air pollution: A study of excess emissions in Texas." PloS one 14(8):e0220696.

Lin, C.-Y. Cynthia, Daniel J Jacob and Arlene M Fiore. 2001. "Trends in exceedances of the ozone air quality standard in the continental United States, 1980-1998." Atmospheric Environment 35(19):3217-3228.

McCoy, Britney J, Paul S Fishbeck and David Gerard. 2010. "How big is big? How often is often? Characterizing Texas petroleum refining upset air emissions." Atmospheric Environment 44:4230-4239.

Miranda, Marie Lynn, Sharon E Edwards, Martha H Keating and Christopher J Paul. 2011. "Making the Environmental Justice Grade: The Relative Burden of Air Pollution Exposure in the United States." International Journal of Environmental Research and Public Health 8(6):17551771.

Monogan, James E, David M Konisky and Neal D Woods. 2017. "Gone with the Wind: Federalism and the Strategic Location of Air Polluters." American Journal of Political Science 61(2):257270.

Morello-Frosch, Rachel, Manuel Pastor and James Sadd. 2001. "Environmental justice and Southern California's "riskscape" the distribution of air toxics exposures and health risks among diverse communities." Urban Affairs Review 36(4):551-578.

Moretti, Enrico and Matthew Neidell. 2011. "Pollution, Health, and Avoidance Behavior: Evidence from the Ports of Los Angeles." Journal of Human Resources 46(1):154-175.

Muller, Nicholas Z. and Robert Mendelsohn. 2012a. "Efficient Pollution Regulation: Getting the Prices Right: Corrigendum (Mortality Rate Update)." American Economic Review 102(1):61316.

URL: http://www.aeaweb.org/articles?id=10.1257/aer.102.1.613

Muller, Nicholas Z. and Robert Mendelsohn. 2012b. Using Marginal Damages in Environmental Policy: A Study of Air Pollution in the United States. 1st ed. Washington D.C.: The American Enterprise Institute for Public Policy Research.

Murphy, Cynthia Folsom and David T Allen. 2005. "Hydrocarbon emissions from industrial release events in the Houston-Galveston area and their impact on ozone formation." Atmospheric Environment 39(21):3785-3798.

Murphy, L Sherry, Jiaquan Xu, Kenneth D Kochanek, Sally Curtin and Elizabeth Arias. 2017. "National Vital Statistics Reports Deaths: Final Data for 2015." National vital statistics reports: from the Centers for Disease Control and Prevention, National Center for Health Statistics, National Vital Statistics System 66:1-75.

Muzhe, Yang and Chou Shin-Yi. 2018. "The impact of environmental regulation on fetal health: Evidence from the shutdown of a coal-fired power plant located upwind of New Jersey." Journal of Environmental Economics and Management 89:94-115.

Nam, Junsang, Yosuke Kimura, William Vizuete, Cynthia Murphy and David T Allen. 2006. "Modeling the impacts of emission events on ozone formation in Houston, Texas." Atmospheric Environment 40(28):5329-5341.

Ozymy, Joshua and Melissa L Jarrell. 2011. "Upset over air pollution: Analyzing upset event emissions at petroleum refineries." Review of Policy Research 28(4):365-382.

Pope, C. Arden, Jacob S. Lefler, Majid Ezzati, Joshua D. Higbee, Julian D. Marshall, Sun-Young Kim, Matthew Bechle, Kurtis S. Gilliat, Spencer E. Vernon, Allen L. Robinson and Richard T. Burnett. 2019. "Mortality Risk and Fine Particulate Air Pollution in a Large, Representative Cohort of U.S. Adults." Environmental Health Perspectives 127(7):077007.

Pope III, C Arden, Richard T Burnett, Michael J Thun, Eugenia E Calle, Daniel Krewski, Kazuhiko Ito and George D Thurston. 2002. "Lung cancer, cardiopulmonary mortality, and long-term exposure to fine particulate air pollution." JAMA 287(9):1132-1141. 
Ransom, Michael R and C Arden Pope III. 1995. "External health costs of a steel mill." Contemporary Economic Policy 13(2):86.

Revesz, Richard L and Jack Leinke. 2016. Struggling for Air: Power Plants and the "War on Coal”. Oxford University Press.

Selden, Thomas M, Anne S Forrest and James E Lockhart. 1999. "Analyzing the Reductions in U.S. Air Pollution Emissions: 1970 to 1990.” Land Economics 75(1):1-21.

Sierra Club. 2011. "Petition to Find Inadequate and Correct Several State Implementation Plans under Section 110 of the Clean Air Act Due to Startup, Shutdown, Malfunction, and/or Maintenance Provisions.".

Smith, Richard L, Baowei Xu and Paul Switzer. 2009. "Reassessing the relationship between ozone and short-term mortality in US urban communities." Inhalation toxicology 21(sup2):37-61.

Sutton, Mark A., Stefan Reis and Samantha M.H. Baker, eds. 2009. Atmospheric Ammonia: Detecting emission changes and environmental impacts. Springer Science + Business Media B.V.

Texas Commission on Environmental Quality. 2016. "Texas Administrative Code: General Air Quality Rules. Rule 101.201: Emissions Events Reporting and Recordkeeping Requirements.”.

Texas House of Representatives. 2001. "H.B. 2912, Texas 77th Legislative Session.”.

Vizuete, William, Byeong-Uk Kim, Harvey Jeffries, Yosuke Kimura, David T Allen, MarianthiAnna Kioumourtzoglou, Leiran Biton and Barron Henderson. 2008. "Modeling ozone formation from industrial emission events in Houston, Texas." Atmospheric Environment 42(33):76417650.

Zirogiannis, Nikolaos, Alex J. Hollingsworth and David M. Konisky. 2018. "Understanding Excess Emissions from Industrial Facilities: Evidence from Texas." Environmental Science \& Technology 52(5):2482-2490.

URL: http://pubs.acs.org/doi/10.1021/acs.est.7b04887

Zou, X. and Yonghui Wu. 2005. "On the Relationship between Total Ozone Mapping Spectrometer (TOMS) Ozone and Hurricanes." 110(D6):1-15.

URL: http://doi.wiley.com/10.1029/2004JD005019 
Table 1: Emissions event by event type (scheduled vs. unplanned) and report type (initial vs. final) in the censored dataset

\begin{tabular}{lcccc}
\hline & & & & \\
\hline Event type & Initial Report & Final Report & Total & Share of total \\
\hline Scheduled Shutdown & 128 & 917 & 1,045 & 0.02 \\
Scheduled Startup & 161 & 1,663 & 1,824 & 0.04 \\
Scheduled Maintenance & 424 & 4,520 & 4,944 & 0.11 \\
Emissions Event & 3,963 & 33,450 & 37,413 & 0.83 \\
Total & 4,676 & 40,550 & 45,231 & \\
\hline
\end{tabular}

Note: In this table, emissions events refer to unplanned start-up, shutdown or malfunction events. Initial reports become de facto final reports when no final report is submitted within two weeks of the ending date of an event.

Source: TCEQ Air Emissions and Maintenance Events (AEME) dataset. 
Figure 1: Number of facilities reporting to the TCEQ (left vertical axis) and number of excess emissions events (right vertical axis) by year in the censored dataset

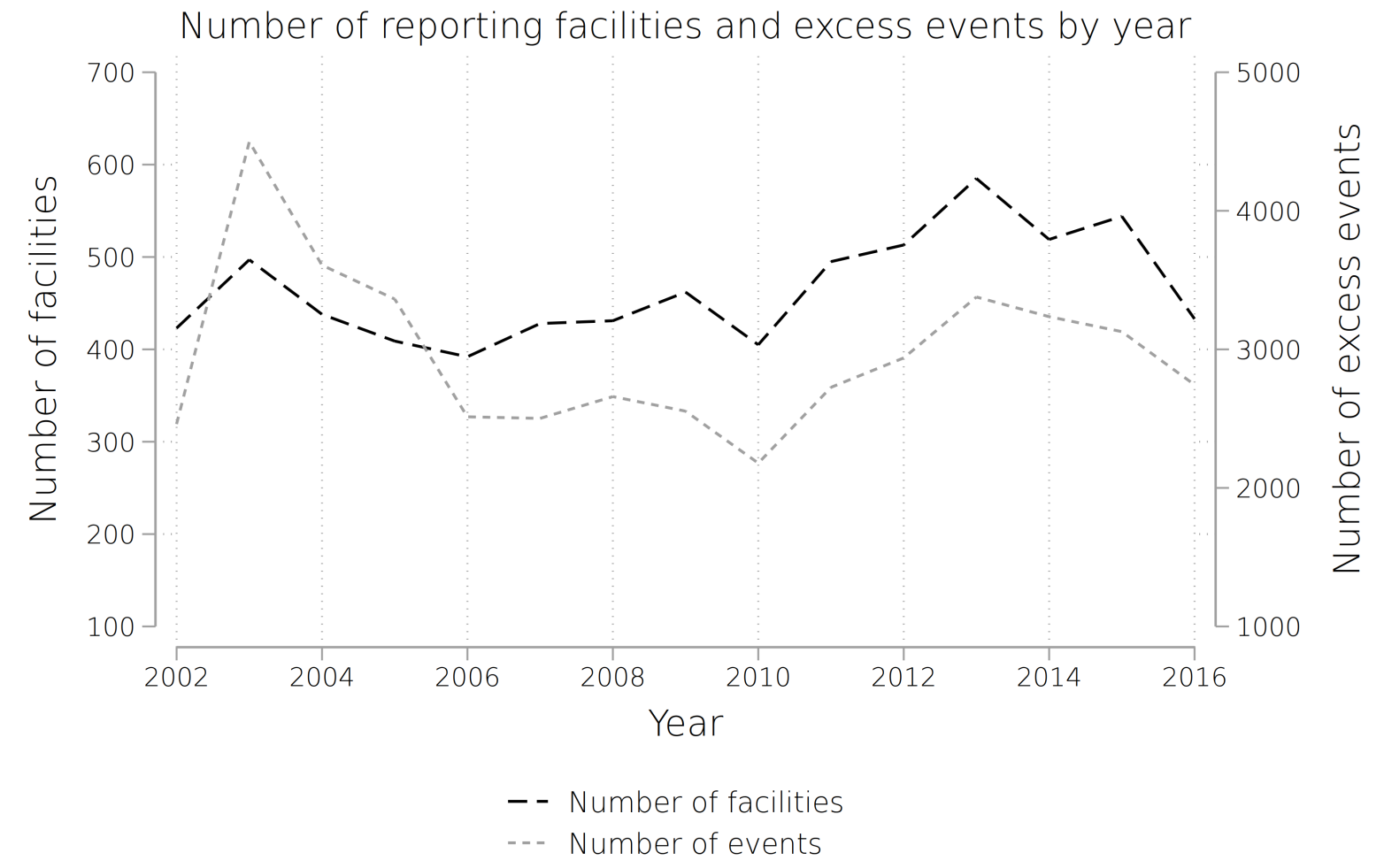

Source: TCEQ Air Emissions and Maintenance Events (AEME) dataset. 
Table 2: Summary statistics for data used in air pollution and mortality specifications

\begin{tabular}{|c|c|c|c|c|c|c|}
\hline & Mean & S.D. & Min. & Max. & $\mathrm{N}$ & Unique $\mathrm{N}$. \\
\hline \multicolumn{7}{|l|}{ Pollution readings } \\
\hline $\mathrm{O}_{3}, \mathrm{ppb}$ & 29.13 & 12.01 & 0.00 & 97.50 & 406314 & 86 \\
\hline \multicolumn{7}{|l|}{ Weather data } \\
\hline Air temperature, $\mathrm{C}$ & 19.56 & 7.97 & -18.93 & 35.50 & 516556 & 212 \\
\hline Precipitable water, $\mathrm{kg} / \mathrm{m}^{2}$ & 25.96 & 13.41 & 0.03 & 71.35 & 516556 & 212 \\
\hline Surface pressure, $\mathrm{kPa}$ & 98.65 & 5.38 & 81.93 & 104.60 & 516556 & 212 \\
\hline Relative humidity, $\%$ & 69.82 & 19.51 & 0.00 & 100.00 & 516556 & 212 \\
\hline Wind speed, $\mathrm{m} / \mathrm{s}$ & 4.59 & 2.20 & 0.00 & 16.25 & 516556 & 212 \\
\hline \multicolumn{7}{|l|}{ Excess Emissions, daily } \\
\hline $\mathrm{VOC} \leq 15 \mathrm{mi}$, tons & 0.39 & 5.52 & 0.00 & 386.94 & 516556 & 212 \\
\hline $\mathrm{NH}_{3} \leq 15 \mathrm{mi}$, tons & 0.00 & 0.04 & 0.00 & 6.90 & 516556 & 212 \\
\hline $\mathrm{SO}_{2} \leq 15 \mathrm{mi}$, tons & 0.22 & 4.21 & 0.00 & 558.09 & 516556 & 212 \\
\hline $\mathrm{NO}_{x} \leq 15 \mathrm{mi}$, tons & 0.03 & 0.42 & 0.00 & 33.77 & 516556 & 212 \\
\hline $\mathrm{CO} \leq 15 \mathrm{mi}$, tons & 0.22 & 4.42 & 0.00 & 462.06 & 516556 & 212 \\
\hline $\mathrm{PM} \leq 15 \mathrm{mi}$, tons & 0.01 & 0.21 & 0.00 & 35.00 & 516556 & 212 \\
\hline \multicolumn{7}{|l|}{ Mortality data, monthly } \\
\hline \multicolumn{7}{|l|}{ All deaths per $100 k$} \\
\hline $65+$ & 407.57 & 238.29 & 0.00 & 12036.42 & 46482 & 254 \\
\hline $65-74$ & 182.34 & 195.39 & 0.00 & 12500.00 & 45798 & 251 \\
\hline $75-84$ & 440.53 & 388.94 & 0.00 & 25000.00 & 45921 & 252 \\
\hline $85+$ & 1276.69 & 1253.51 & 0.00 & 100000.00 & 45801 & 250 \\
\hline \multicolumn{7}{|l|}{ Population, $1 k$} \\
\hline $65+$ & 9.85 & 29.91 & 0.00 & 453.17 & 46482 & 254 \\
\hline $65-74$ & 5.90 & 18.30 & 0.00 & 297.10 & 46482 & 254 \\
\hline $75-84$ & 3.26 & 9.53 & 0.00 & 126.42 & 46482 & 254 \\
\hline $85+$ & 1.20 & 3.55 & 0.00 & 50.46 & 46482 & 254 \\
\hline
\end{tabular}

Source: Daily pollution data are provided by the Environmental Pollution Agency's pre-generated daily files. Daily weather data are extracted from the National Oceanic and Atmospheric Administration's NCEP-NCAR Reanalysis 1 model. Excess emissions data are from the censored dataset and are calculated by the authors using data provided by the Texas Commission on Environmental Quality. Mortality micro-data come from the Centers for Disease Control and Prevention Multiple Cause of Death (MCOD) files for 2002-2017. Population data come from the Surveillance, Epidemiology, and End Results (SEER) program, which is supported by the National Cancer Institute. Unique N, refers to the unique number of cross-sectional units observed in our data, while $\mathrm{N}$ refers to the total number of observations. 
Table 3: The relationship between excess emissions and nearby daily ozone concentrations.

\begin{tabular}{llcl}
\hline & VOC & CO & $\mathrm{NO}_{x}$ \\
\hline Excess emissions $\leq$ 15mi, 100 tons & $\begin{array}{l}3.679 * * * \\
(0.730)\end{array}$ & $\begin{array}{c}6.596 * * * \\
(0.998)\end{array}$ & $\begin{array}{l}66.202 * * * \\
(4.979)\end{array}$ \\
\hline Monitor-by-year fixed-effects & Yes & Yes & Yes \\
Week-of-year fixed-effects & Yes & Yes & Yes \\
Hurricane months included & No & No & No \\
Censored dataset & Yes & Yes & Yes \\
Controls & Yes & Yes & Yes \\
\hline Observations & 329573 & 306304 & 306958 \\
\hline
\end{tabular}

Note: Robust standard errors clustered at the monitor-level are reported in parentheses. The model includes monitor-by-year fixed effects, week fixed effects and weather variables (temperature, pressure, relative humidity, percipitable water and wind speed). The dataset used in this analysis are from the most conservative dataset that only only uses the emissions portion of excess emissions events above the permitted level (i.e. the censored dataset) and does not include hurricane months. The dependent variable is the mean of daily ozone concentrations measured in ppb. Each column represents a separate regression where the independent variable of interest differs. 
Figure 2: The relationship between tons of excess emissions and average daily ozone concentrations across distance.

\section{Effect on mean daily ozone concentration (ppb)}

A. Mutually exclusive distance bins
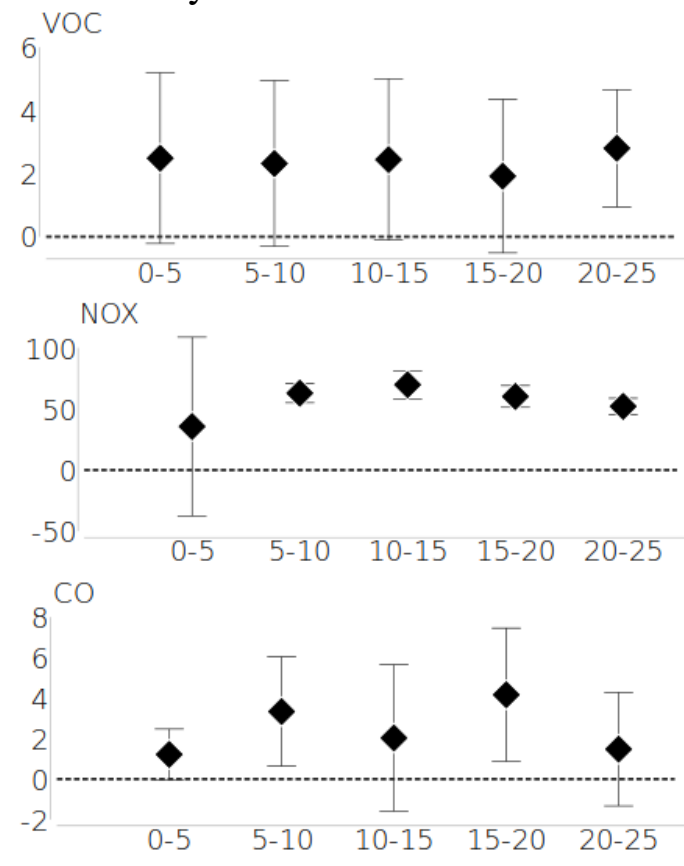

B. Overlapping distance bins
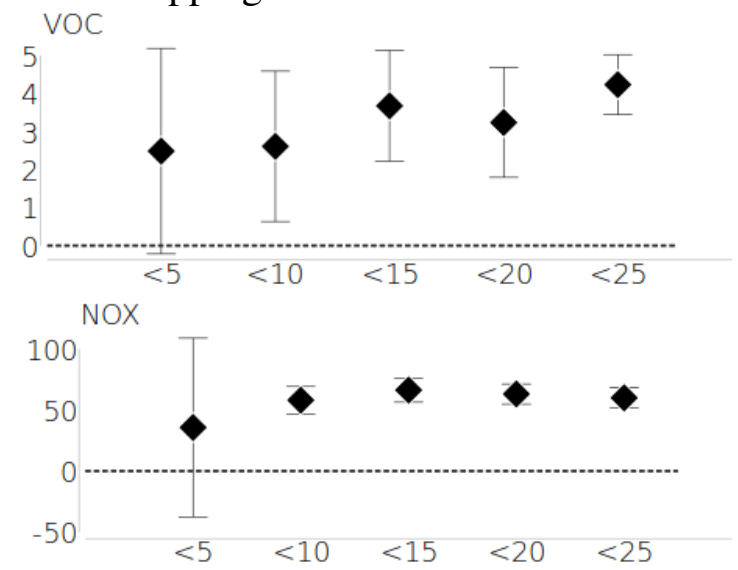

$\mathrm{CO}$

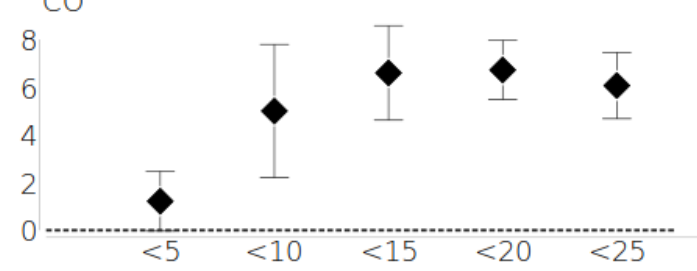

Note: This figure presents two sets of results that use the untransformed mean of daily ozone concentration as the dependent variable. Both sets of results (both left and right panel) use our preferred specification specification (monitorby-year fixed effects, week fixed effects and weather variables included). Brackets represent $95 \%$ confidence intervals, calculated from robust standard errors clustered at the monitor-level. The dataset used in both sets of results considers the censored portion of excess emissions and excludes hurricane months. The left panel considers mutually exclusive distance bins of 0-5 miles, 5-10 miles, etc. The right panel considers overlapping distance bins of 0-5 miles, 0-10 miles, etc. 
Figure 3: The effect of excess emissions on ozone concentrations in event time.

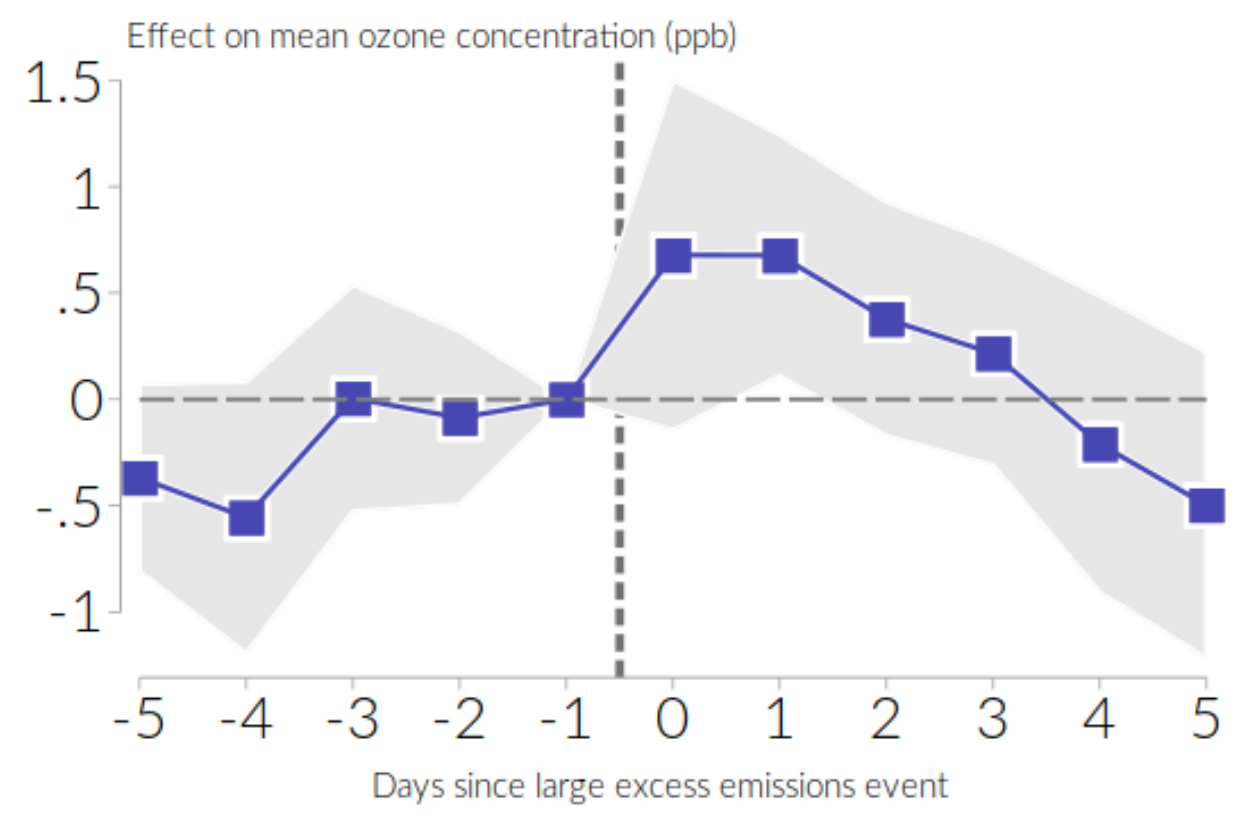

Note: Numbers index days since most recent large excess emissions event. A large excess emissions event is at the $95^{\text {th }}$ percentile by total tons of pollutants emitted. Point estimates are depicted by blue squares and come from a single regression that controls for daily weather, monitor-by-year fixed effects, and week fixed effects. 95\% confidence intervals are displayed by gray area and are calculated using robust standard errors clustered at the monitor level. 
Figure 4: The relationship between excess emissions and all-cause elderly mortality.

Effect on all-cause elderly mortality rate
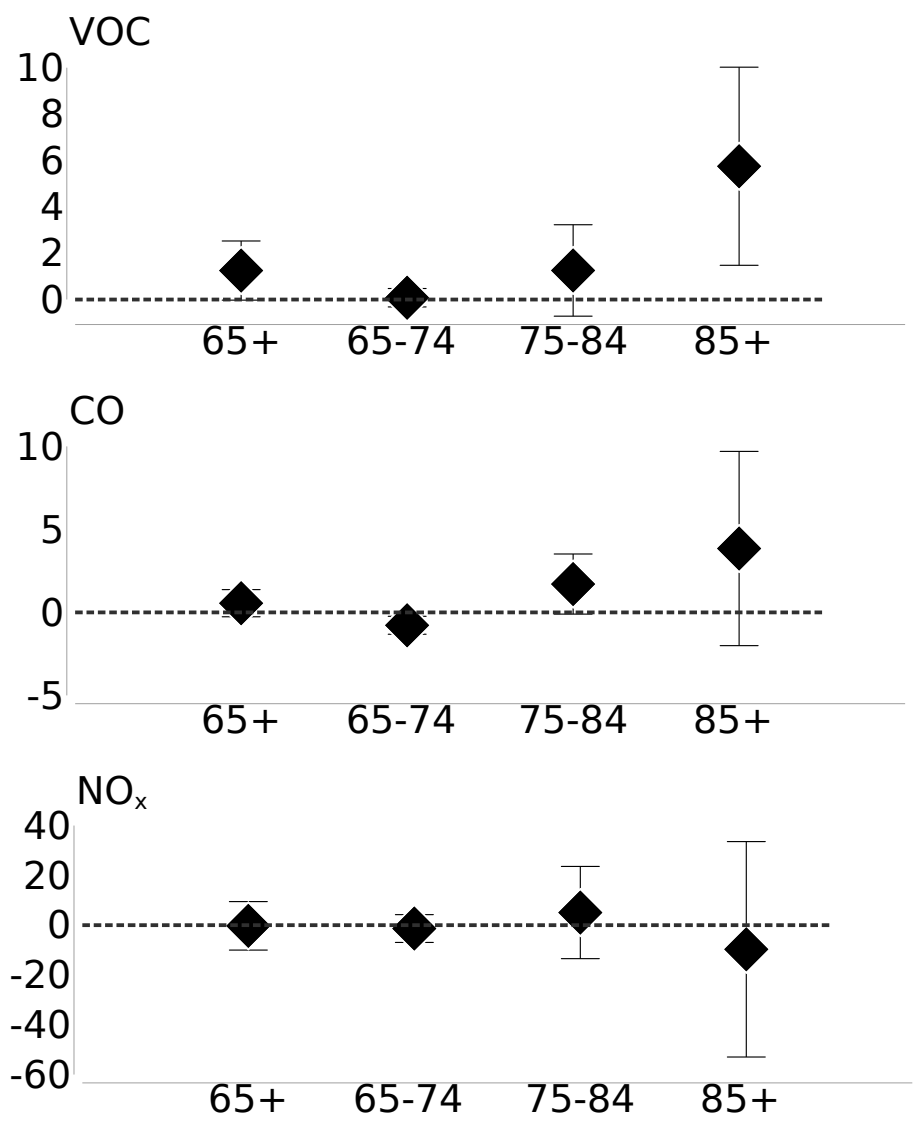

Note: Brackets represent $95 \%$ confidence intervals, calculated from robust standard errors clustered at the county-level, using our preferred specification (county-by-year and month fixed effects). Results are based on our most conservative dataset that only uses the emissions portion of events above the permitted level (i.e. the censored dataset) and does not include hurricane months. 
Table 4: First stage results demonstrating the relationship between monthly excess emissions and ozone pollution using different measures of pollution at the county-month level.

\begin{tabular}{|c|c|c|c|c|c|c|}
\hline & $\begin{array}{l}(1) \\
\text { Mean }\end{array}$ & $\begin{array}{c}(2) \\
\text { Median }\end{array}$ & $\begin{array}{c}(3) \\
75^{\text {th }} \mathrm{pct}\end{array}$ & $\begin{array}{c}(4) \\
95^{\text {th }} \mathrm{pct}\end{array}$ & $\begin{array}{c}(5) \\
99^{t h} \mathrm{pct}\end{array}$ & $\begin{array}{l}\text { (6) } \\
\text { Max }\end{array}$ \\
\hline \multicolumn{7}{|c|}{ Ozone measure, weighted by pop $65+$} \\
\hline Excess VOC, 100 tons & $\begin{array}{c}0.27 * * \\
(0.10)\end{array}$ & $\begin{array}{l}0.23^{* *} \\
(0.09)\end{array}$ & $\begin{array}{l}0.31 * * * \\
(0.11)\end{array}$ & $\begin{array}{l}0.40^{* * * *} \\
(0.10)\end{array}$ & $\begin{array}{l}0.47 * * * \\
(0.12)\end{array}$ & $\begin{array}{l}0.46^{* * * *} \\
(0.13)\end{array}$ \\
\hline Excess $\mathrm{NO}_{x}, 100$ tons & $\begin{array}{c}2.22 \\
(2.60)\end{array}$ & $\begin{array}{c}0.97 \\
(2.41)\end{array}$ & $\begin{array}{c}3.99 \\
(2.67)\end{array}$ & $\begin{array}{l}4.89 * * \\
(2.13)\end{array}$ & $\begin{array}{l}3.98 * \\
(2.07)\end{array}$ & $\begin{array}{l}4.55^{* * *} \\
(1.50)\end{array}$ \\
\hline Excess CO, 100 tons & $\begin{array}{c}-0.01 \\
(0.07)\end{array}$ & $\begin{array}{c}0.07 \\
(0.07)\end{array}$ & $\begin{array}{c}-0.10^{* *} \\
(0.05)\end{array}$ & $\begin{array}{c}-0.14 \\
(0.08)\end{array}$ & $\begin{array}{l}0.32 * * * \\
(0.05)\end{array}$ & $\begin{array}{c}0.09 \\
(0.09)\end{array}$ \\
\hline Mean ozone measure & 29.11 & 28.40 & 35.20 & 44.73 & 49.86 & 51.43 \\
\hline KP F-Stat & 11.25 & 16.84 & 3.89 & 15.30 & 27.32 & 75.74 \\
\hline \multicolumn{7}{|c|}{ Ozone measure, weighted by pop 65-74 } \\
\hline Excess VOC, 100 tons & $\begin{array}{l}0.26^{* *} \\
(0.10)\end{array}$ & $\begin{array}{l}0.23^{* *} \\
(0.09)\end{array}$ & $\begin{array}{l}0.30 \text { **** } \\
(0.11)\end{array}$ & $\begin{array}{l}0.39 * * * \\
(0.10)\end{array}$ & $\begin{array}{l}0.46^{* * * *} \\
(0.11)\end{array}$ & $\begin{array}{l}0.45^{* * *} \\
(0.12)\end{array}$ \\
\hline Excess $\mathrm{NO}_{x}, 100$ tons & $\begin{array}{c}2.51 \\
(2.61)\end{array}$ & $\begin{array}{c}1.24 \\
(2.43)\end{array}$ & $\begin{array}{c}4.35 \\
(2.61)\end{array}$ & $\begin{array}{l}5.18 * * \\
(2.09)\end{array}$ & $\begin{array}{l}4.25^{* *} \\
(2.06)\end{array}$ & $\begin{array}{l}4.59 \text { *** } \\
(1.47)\end{array}$ \\
\hline Excess CO, 100 tons & $\begin{array}{c}-0.03 \\
(0.07)\end{array}$ & $\begin{array}{c}0.06 \\
(0.07)\end{array}$ & $\begin{array}{c}-0.12 * * \\
(0.05)\end{array}$ & $\begin{array}{c}-0.15^{*} \\
(0.08)\end{array}$ & $\begin{array}{l}0.31^{* * * *} \\
(0.05)\end{array}$ & $\begin{array}{c}0.07 \\
(0.10)\end{array}$ \\
\hline Mean ozone measure & 29.13 & 28.44 & 35.22 & 44.72 & 49.83 & 51.39 \\
\hline KP F-Stat & 11.51 & 16.55 & 4.33 & 17.30 & 28.04 & 62.81 \\
\hline \multicolumn{7}{|c|}{ Ozone measure, weighted by pop 75-84 } \\
\hline Excess VOC, 100 tons & $\begin{array}{l}0.27 * * \\
(0.13)\end{array}$ & $\begin{array}{l}0.23^{* *} \\
(0.11)\end{array}$ & $\begin{array}{l}0.31^{* *} \\
(0.13)\end{array}$ & $\begin{array}{l}0.42^{* * * *} \\
(0.13)\end{array}$ & $\begin{array}{l}0.50 * * * \\
(0.14)\end{array}$ & $\begin{array}{l}0.48^{* * * *} \\
(0.15)\end{array}$ \\
\hline Excess $\mathrm{NO}_{x}, 100$ tons & $\begin{array}{c}2.33 \\
(2.53)\end{array}$ & $\begin{array}{c}1.07 \\
(2.31)\end{array}$ & $\begin{array}{c}4.04 \\
(2.62)\end{array}$ & $\begin{array}{l}4.87 * * \\
(2.12)\end{array}$ & $\begin{array}{c}3.95^{*} \\
(2.09)\end{array}$ & $\begin{array}{l}4.36^{* * * *} \\
(1.56)\end{array}$ \\
\hline Excess CO, 100 tons & $\begin{array}{c}-0.02 \\
(0.07)\end{array}$ & $\begin{array}{c}0.07 \\
(0.07)\end{array}$ & $\begin{array}{c}-0.11 * * \\
(0.05)\end{array}$ & $\begin{array}{c}-0.14 \\
(0.08)\end{array}$ & $\begin{array}{l}0.30 * * * \\
(0.05)\end{array}$ & $\begin{array}{c}0.07 \\
(0.10)\end{array}$ \\
\hline Mean ozone measure & 29.11 & 28.39 & 35.22 & 44.80 & 49.98 & 51.55 \\
\hline KP F-Stat & 6.56 & 10.37 & 3.30 & 8.90 & 18.77 & 55.97 \\
\hline \multicolumn{7}{|c|}{ Ozone measure, weighted by pop $85+$} \\
\hline Excess VOC, 100 tons & $\begin{array}{l}0.24 * * \\
(0.12)\end{array}$ & $\begin{array}{l}0.21^{* *} \\
(0.09)\end{array}$ & $\begin{array}{l}0.28 * * \\
(0.12)\end{array}$ & $\begin{array}{l}0.36^{* * * *} \\
(0.11)\end{array}$ & $\begin{array}{l}0.43 * * * \\
(0.12)\end{array}$ & $\begin{array}{l}0.42^{* * *} \\
(0.13)\end{array}$ \\
\hline Excess $\mathrm{NO}_{x}, 100$ tons & $\begin{array}{c}2.33 \\
(2.55)\end{array}$ & $\begin{array}{c}1.09 \\
(2.35)\end{array}$ & $\begin{array}{c}4.06 \\
(2.66)\end{array}$ & $\begin{array}{l}5.04 * * \\
(2.07)\end{array}$ & $\begin{array}{l}4.18 * * \\
(1.99)\end{array}$ & $\begin{array}{l}4.83 * * * \\
(1.30)\end{array}$ \\
\hline Excess CO, 100 tons & $\begin{array}{c}0.00 \\
(0.09)\end{array}$ & $\begin{array}{c}0.09 \\
(0.09)\end{array}$ & $\begin{array}{c}-0.09 \\
(0.06)\end{array}$ & $\begin{array}{c}-0.12 \\
(0.10)\end{array}$ & $\begin{array}{l}0.33^{* * * *} \\
(0.05)\end{array}$ & $\begin{array}{c}0.11 \\
(0.13)\end{array}$ \\
\hline Mean ozone measure & 29.16 & 28.46 & 35.25 & 44.73 & 49.85 & 51.36 \\
\hline KP F-Stat & 14.23 & 18.53 & 3.35 & 17.01 & 32.35 & 81.00 \\
\hline KP F-Stat Critical Value & 9.08 & 9.08 & 9.08 & 9.08 & 9.08 & 9.08 \\
\hline Observations & 5947 & 5947 & 5947 & 5947 & 5947 & 5947 \\
\hline Weather Controls & Yes & Yes & Yes & Yes & Yes & Yes \\
\hline Month FE & Yes & Yes & Yes & Yes & Yes & Yes \\
\hline County-by-Year FE & Yes & Yes & Yes & Yes & Yes & Yes \\
\hline Clustered Standard Errors & County & County & County & County & County & County \\
\hline
\end{tabular}

Note: $* \mathrm{p}<0.1, * * \mathrm{p}<0.05, * * * \mathrm{p}<0.01$. Robust standard errors clustered at the county level in parentheses. Each regression is weighted by the county population of the relevant subgroup. 
Table 5: Second stage results demonstrating the relationship between ozone and elderly mortality using different measures of pollution at the county-month level.

\begin{tabular}{|c|c|c|c|c|c|c|}
\hline & $\begin{array}{c}(1) \\
\text { Mean }\end{array}$ & $\begin{array}{c}(2) \\
\text { Median }\end{array}$ & $\begin{array}{c}(3) \\
75^{\text {th }} \mathrm{pct}\end{array}$ & $\begin{array}{c}\text { (4) } \\
95^{\text {th }} \mathrm{pct}\end{array}$ & $\begin{array}{c}(5) \\
99^{t h} \mathrm{pct}\end{array}$ & $\begin{array}{l}\text { (6) } \\
\text { Max }\end{array}$ \\
\hline \multicolumn{7}{|l|}{ All cause mortality, $65+$} \\
\hline$\widehat{\text { Ozone }}$ & $\begin{array}{c}4.41 * \\
(2.26)\end{array}$ & $\begin{array}{l}6.01 * * * \\
(1.78)\end{array}$ & $\begin{array}{c}2.87 \\
(2.13)\end{array}$ & $\begin{array}{c}2.30 \\
(1.61)\end{array}$ & $\begin{array}{l}2.39 * * \\
(1.14)\end{array}$ & $\begin{array}{c}2.39 * \\
(1.31)\end{array}$ \\
\hline Mean death rate & 378.80 & 378.80 & 378.80 & 378.80 & 378.80 & 378.80 \\
\hline Mean ozone measure & 29.11 & 28.40 & 35.20 & 44.73 & 49.86 & 51.43 \\
\hline KP F-Stat & 11.25 & 16.84 & 3.89 & 15.30 & 27.32 & 75.74 \\
\hline$\%$ Texas pop in sample & 67.32 & 67.32 & 67.32 & 67.32 & 67.32 & 67.32 \\
\hline \multicolumn{7}{|l|}{ All cause mortality, $65-74$} \\
\hline$\widehat{\text { Ozone }}$ & $\begin{array}{c}0.08 \\
(0.86)\end{array}$ & $\begin{array}{c}0.28 \\
(0.84)\end{array}$ & $\begin{array}{c}-0.09 \\
(0.73)\end{array}$ & $\begin{array}{c}-0.04 \\
(0.58)\end{array}$ & $\begin{array}{c}-0.11 \\
(0.43)\end{array}$ & $\begin{array}{c}-0.04 \\
(0.50)\end{array}$ \\
\hline Mean death rate & 161.43 & 161.43 & 161.43 & 161.43 & 161.43 & 161.43 \\
\hline Mean ozone measure & 29.13 & 28.44 & 35.22 & 44.72 & 49.83 & 51.39 \\
\hline KP F-Stat & 11.51 & 16.55 & 4.33 & 17.30 & 28.04 & 62.81 \\
\hline$\%$ Texas pop in sample & 68.42 & 68.42 & 68.42 & 68.42 & 68.42 & 68.42 \\
\hline \multicolumn{7}{|l|}{ All cause mortality, 75-84 } \\
\hline$\widehat{\text { Ozone }}$ & $\begin{array}{c}4.73 \\
(3.31)\end{array}$ & $\begin{array}{l}7.06^{* *} \\
(2.73)\end{array}$ & $\begin{array}{c}2.86 \\
(2.76)\end{array}$ & $\begin{array}{c}2.29 \\
(2.00)\end{array}$ & $\begin{array}{l}3.08 * * \\
(1.37)\end{array}$ & $\begin{array}{c}2.82 * \\
(1.60)\end{array}$ \\
\hline Mean death rate & 415.21 & 415.21 & 415.21 & 415.21 & 415.21 & 415.21 \\
\hline Mean ozone measure & 29.11 & 28.39 & 35.22 & 44.80 & 49.98 & 51.55 \\
\hline KP F-Stat & 6.56 & 10.37 & 3.30 & 8.90 & 18.77 & 55.97 \\
\hline$\%$ Texas pop in sample & 66.18 & 66.18 & 66.18 & 66.18 & 66.18 & 66.18 \\
\hline \multicolumn{7}{|l|}{ All cause mortality, $85+$} \\
\hline$\widehat{\text { Ozone }}$ & $\begin{array}{l}20.70 * * \\
(9.99)\end{array}$ & $\begin{array}{l}26.84 * * * \\
(8.59)\end{array}$ & $\begin{array}{l}13.87 \\
(8.91)\end{array}$ & $\begin{array}{l}11.04 \\
(6.92)\end{array}$ & $\begin{array}{l}10.26^{*} \\
(5.56)\end{array}$ & $\begin{array}{l}10.73 \\
(6.52)\end{array}$ \\
\hline Mean death rate & 1163.45 & 1163.45 & 1163.45 & 1163.45 & 1163.45 & 1163.45 \\
\hline Mean ozone measure & 29.16 & 28.46 & 35.25 & 44.73 & 49.85 & 51.36 \\
\hline KP F-Stat & 14.23 & 18.53 & 3.35 & 17.01 & 32.35 & 81.00 \\
\hline$\%$ Texas pop in sample & 66.96 & 66.96 & 66.96 & 66.96 & 66.96 & 66.96 \\
\hline KP F-Stat Critical Value & 9.08 & 9.08 & 9.08 & 9.08 & 9.08 & 9.08 \\
\hline Observations & 5947 & 5947 & 5947 & 5947 & 5947 & 5947 \\
\hline Weather Controls & Yes & Yes & Yes & Yes & Yes & Yes \\
\hline Month FE & Yes & Yes & Yes & Yes & Yes & Yes \\
\hline County-by-Year FE & Yes & Yes & Yes & Yes & Yes & Yes \\
\hline Clustered Standard Errors & County & County & County & County & County & County \\
\hline
\end{tabular}

Note: $* \mathrm{p}<0.1, * * \mathrm{p}<0.05, * * * \mathrm{p}<0.01$. Robust standard errors clustered at the county level in parentheses. Each regression is weighted by the county population of the relevant subgroup. 
Figure 5: Expected damages from excess emissions

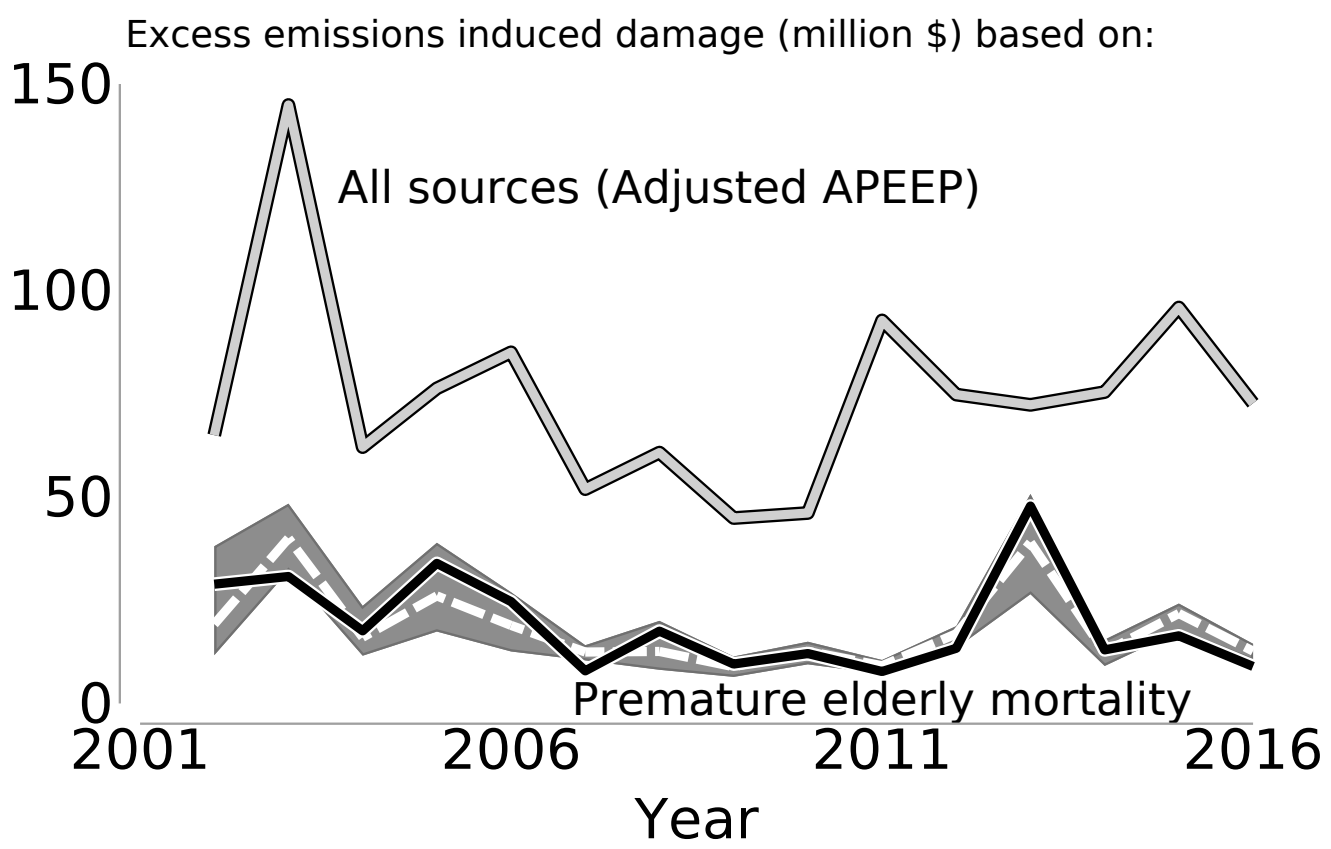

Note: Damages are reported in 2019 \$. The solid grey line represents harvesting adjusted APEEP damage estimates (Deryugina et al. 2019). APEEP damage estimates account for mortality, morbidity, and other damages that occur as a result of pollution (Muller and Mendelsohn 2012a). The solid black line represents damages from 65+ premature mortality from excess emissions using our OLS estimates described in Section 4.2. The white dashed line represents damage estimates based on IV specifications that use mean monthly ozone as an instrumental variable. For clarity, we do not present specific damage estimates based on our other IV estimates since there is substantial overlap. However, these results are quite similar to the mean monthly ozone based results and we present the range of these estimates for any given year using the grey shaded area. Average annual damage estimates are-in millions-\$74.7 (adjusted APPEP); \$19.3 (elderly mortality, OLS); $\$ 18.6$ (elderly mortality, IV using mean monthly ozone); $\$ 13.6$ (elderly mortality, IV using $75^{\text {th }}$ percentile monthly ozone); $\$ 13.8$ (elderly mortality, IV using $95^{\text {th }}$ percentile monthly ozone); $\$ 23.8$ (elderly mortality, IV using $99^{\text {th }}$ percentile monthly ozone); and $\$ 19.8$ (elderly mortality, IV using max monthly ozone). 


\section{Appendix}

In order to clarify the way the TCEQ defines emissions during malfunctions as well as scheduled or unscheduled start-ups, shutdowns or malfunctions, we provide the relevant section from the Texas Administrative Code (TAC) where each term is explained:

TAC 101.1: Definitions

Emissions Event: Any upset event or unscheduled maintenance, start-up, or shutdown activity, from a common cause that results in unauthorized emissions of air contaminants from one or more emissions points at a regulated entity.

Scheduled maintenance, start-up, or shutdown activity: For activities with unauthorized emissions that are expected to exceed a reportable quantity (RQ), a scheduled maintenance, startup, or shutdown activity is an activity that the owner or operator of the regulated entity whether performing or otherwise affected by the activity, provides prior notice and a final report as required by $\S 101.211$ of this title (relating to Scheduled Maintenance, Start-up, and Shutdown Reporting and Record keeping Requirements); the notice or final report includes the information required in $\S 101.211$ of this title; and the actual unauthorized emissions from the activity do not exceed the emissions estimates submitted in the initial notification by more than an RQ. For activities with unauthorized emissions that are not expected to, and do not, exceed an RQ, a scheduled maintenance, start-up, or shutdown activity is one that is recorded as required by $\S 101.211$ of this title. Expected excess opacity events as described in $§ 101.201(\mathrm{e})$ of this title (relating to Emissions Event Reporting and Record keeping Requirements) resulting from scheduled maintenance, startup, or shutdown activities are those that provide prior notice (if required), and are recorded and reported as required by $\S 101.211$ of this title.

Unauthorized emissions: Emissions of any air contaminant except water, nitrogen, ethane, noble gases, hydrogen, and oxygen that exceed any air emission limitation in a permit, rule, or order of the commission or as authorized by Texas Health and Safety Code, $\S 382.0518(\mathrm{~g})$.

Unplanned maintenance, start-up, or shutdown activity: For activities with unauthorized emissions that are expected to exceed a reportable quantity or with excess opacity, an unplanned maintenance, start-up, or shutdown activity is: (A) a start-up or shutdown that was not part of normal or routine facility operations, is unpredictable as to timing, and is not the type of event normally authorized by permit; or (B) a maintenance activity that arises from sudden and unforeseeable events beyond the control of the operator that requires the immediate corrective action to minimize or avoid an upset or malfunction.

Upset event: An unplanned and unavoidable breakdown or excursion of a process or operation that results in unauthorized emissions. A maintenance, start-up, or shutdown activity that was reported under $\$ 101.211$ of this title (relating to Scheduled Maintenance, Start-up, and Shut- 
down Reporting and Record keeping Requirements), but had emissions that exceeded the reported amount by more than a reportable quantity due to an unplanned and unavoidable breakdown or excursion of a process or operation is an upset event.

Table A1: Emissions event by event type (scheduled vs. unplanned) and report type (initial vs. final) in the full dataset

\begin{tabular}{lcccc}
\hline & & & & \\
\hline Event type & Initial Report & Final Report & Total & Share of total \\
\hline Scheduled Shutdown & 160 & 1,407 & 1,567 & 0.03 \\
Scheduled Startup & 201 & 2,593 & 2,794 & 0.05 \\
Scheduled Maintenance & 510 & 5,917 & 6,427 & 0.12 \\
Emissions Event & 4,448 & 37,094 & 41,542 & 0.79 \\
Total & 5,319 & 47,011 & 52,335 & \\
\hline
\end{tabular}

Note: In this table, emissions events refer to unplanned start-up, shutdown or malfunction events. Initial reports become de facto final reports when no final report is submitted within two weeks of the ending date of an event.

Source: TCEQ Air Emissions and Maintenance Events (AEME) dataset.

Table A2: Percent of event-observations involving each pollutant that also emit other pollutants

\begin{tabular}{|c|c|c|c|c|c|c|c|}
\hline \multirow[b]{2}{*}{ Pollutant } & \multicolumn{6}{|c|}{$\%$ of events involving $\mathrm{X}$ additional pollutants } & \multirow[b]{2}{*}{$\begin{array}{c}\text { \# of events } \\
\text { involving pollutant }\end{array}$} \\
\hline & Zero & One & Two & Three & Four & Five & \\
\hline $\mathrm{CO}$ & 0.021 & 0.107 & 0.425 & 0.324 & 0.107 & 0.016 & 51249 \\
\hline VOC & 0.322 & 0.098 & 0.278 & 0.219 & 0.072 & 0.011 & 75603 \\
\hline $\mathrm{NO}_{x}$ & 0.034 & 0.095 & 0.424 & 0.325 & 0.106 & 0.016 & 51791 \\
\hline $\mathrm{SO}_{2}$ & 0.109 & 0.092 & 0.086 & 0.495 & 0.189 & 0.028 & 28814 \\
\hline $\mathrm{NH}_{3}$ & 0.164 & 0.135 & 0.247 & 0.174 & 0.188 & 0.092 & 8778 \\
\hline PM & 0.078 & 0.095 & 0.074 & 0.218 & 0.448 & 0.087 & 9264 \\
\hline
\end{tabular}

Note: Column label "Zero" shows the share of excess emissions event observations that release a single pollutant. For example, out of the 51,249 event-observations of $\mathrm{CO}$ releases, $2.1 \%$ involve the release of $\mathrm{CO}$ only from a given excess emissions event. Columns labeled "One", "Two", "Three", etc. indicate the share of event-observations that release one, two , three (etc.) additional pollutants. For example out of the 51,791 event-observations of $\mathrm{NO}_{x}$ releases, only $9.5 \%$ involve the release of one additional pollutant (i.e. in addition to $\mathrm{NO}_{x}$ ) 
Figure A1: Number of facilities reporting to the TCEQ and number of excess emissions events by year in the full dataset.

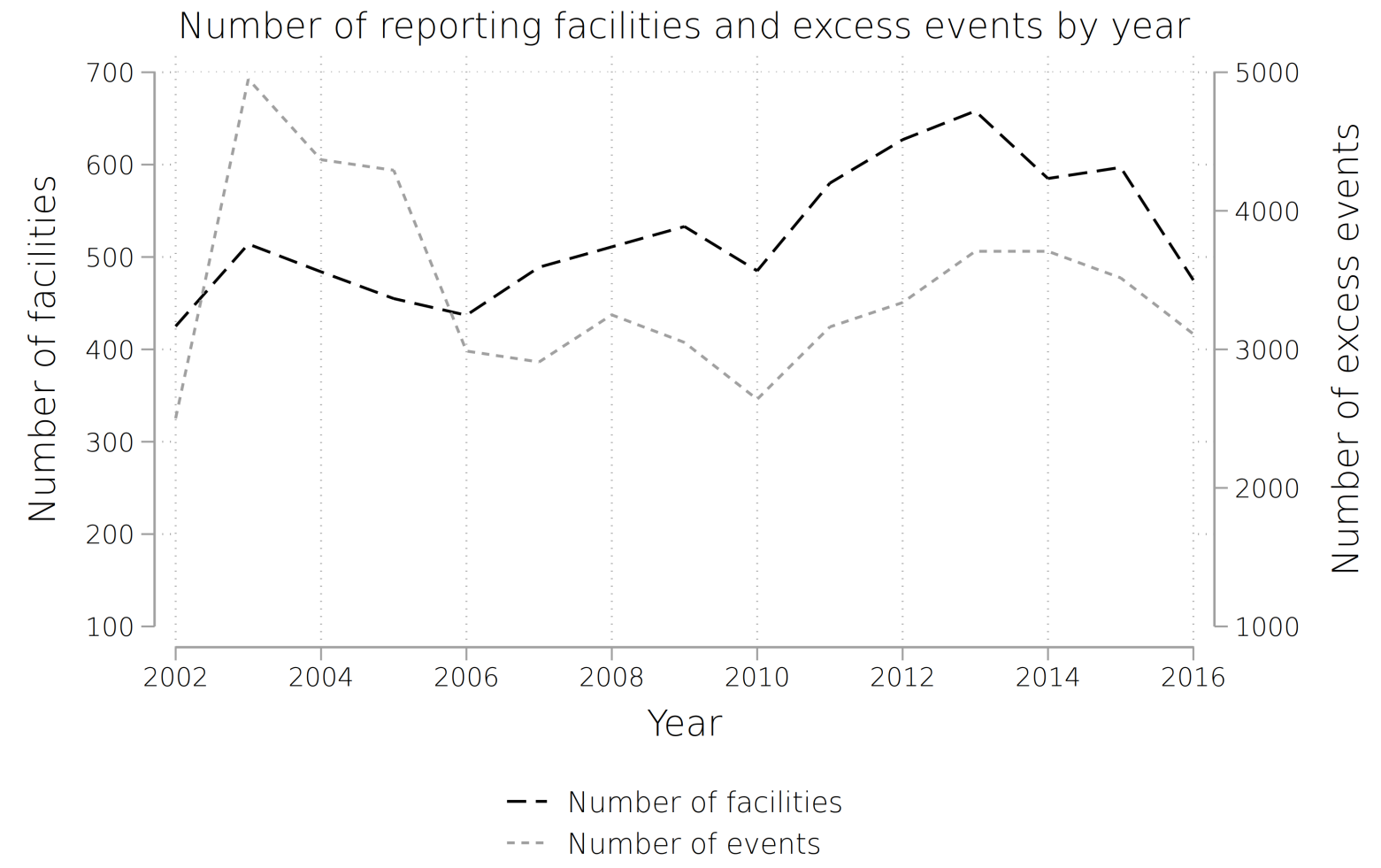

Source: TCEQ Air Emissions and Maintenance Events (AEME) dataset. 
County-year variables: For some specifications we include economic, demographic, and other controls variables at the county-year level. County-level data on the annual unemployment rate and percent of individuals in poverty come from the Bureau of Labor Statistics' Local Area Unemployment Statistics. Annual median income estimates at the county-level come from the U.S. Census Bureau's Small Area Income and Poverty Estimates (www. census.gov/did/www/saipe/). Demographic data are calculated using the SEER population estimates, which report the number of individuals by gender, race, and single year of age for each county and year. Finally, data on the tons of lead emitted in each county and year come from the TRI.

Table A3: Summary statistics for control variables used in specifications without county-by-year fixed effects

\begin{tabular}{lrrrrr}
\hline & Mean & S.D. & Min. & Max. & N \\
\hline Unemp Rate & 0.06 & 0.02 & 0.02 & 0.20 & 45720 \\
\% Non-White & 0.09 & 0.08 & 0.00 & 0.43 & 45720 \\
\% of Hispanic Origin & 0.32 & 0.23 & 0.02 & 0.97 & 45720 \\
\% Elderly & 0.16 & 0.05 & 0.05 & 0.35 & 45708 \\
Median income, \$10k & 4.11 & 1.09 & 1.72 & 9.75 & 45720 \\
\% in Poverty & 17.66 & 5.78 & 4.80 & 45.70 & 45720 \\
Lead emitted from TRI sources (tons) & 5.58 & 32.54 & 0.00 & 1037.23 & 46071 \\
\hline
\end{tabular}


Table A4: The estimated relationship between excess emissions and nearby daily ozone concentrations across different model specifications.

Effect on mean daily ozone concentration (ppb)

\begin{tabular}{lccc}
\hline & Baseline & + Weather & $\begin{array}{c}+ \text { Monitor- } \\
\text { by-year FE }\end{array}$ \\
\hline Excess VOC $\leq 15 \mathrm{mi}, 100$ tons & $\begin{array}{c}3.561^{* * *} \\
(0.933)\end{array}$ & $\begin{array}{c}3.537 * * * \\
(0.787)\end{array}$ & $\begin{array}{c}3.679 * * * \\
(0.730)\end{array}$ \\
Observations & 329573 & 329573 & 329573 \\
\hline Excess CO $\leq 15 \mathrm{mi}, 100$ tons & $6.853^{* * * *}$ & $6.709 * * *$ & $6.596 * * *$ \\
& $(1.079)$ & $(0.917)$ & $(0.998)$ \\
Observations & 306307 & 306307 & 306304 \\
\hline Excess NO $x \leq 15 \mathrm{mi}, 100$ tons & $57.295^{* * *}$ & $63.612 * * *$ & $66.202 * * *$ \\
& $(6.726)$ & $(5.708)$ & $(4.979)$ \\
Observations & 306961 & 306961 & 306958 \\
& & & \\
\hline Monitor fixed-effects & Yes & Yes & No \\
Year fixed-effects & Yes & Yes & No \\
Week fixed-effects & Yes & Yes & Yes \\
Monitor-by-year fixed-effects & No & No & Yes \\
Hurricane months included & No & No & No \\
Censored dataset & Yes & Yes & Yes \\
County clustered standard errors & Yes & Yes & Yes \\
\hline
\end{tabular}

Note: Robust standard errors clustered at the monitor-level are reported in parentheses. The dataset used in these analyses is the most conservative dataset in that it only uses the emissions portion of excess emissions events above the permitted level (i.e. the censored dataset) and it does not include hurricane months. The dependent variable is the untransformed mean of daily ozone concentrations measured in ppb. Column labeled "Baseline" shows results from a model that uses monitor, year and week fixed effects. Column labeled "+Weather" uses the same fixed effects as the "Baseline" specification, but adds weather variables (temperature, relative humidity, surface pressure, percipitable water and wind speed). The last column show results from our preferred specification (also presented in Table 3 of the main manuscript). This specification uses the same set of weather variables mentioned above, but with a set of monitor-by-year (instead of monitor and year) fixed effects. 
Figure A2: The estimated relationship between excess emissions and nearby daily ozone concentrations across different datasets and distances.

\section{Effect on mean daily ozone concentration (ppb)}

\section{A. Mutually exclusive distance bins}

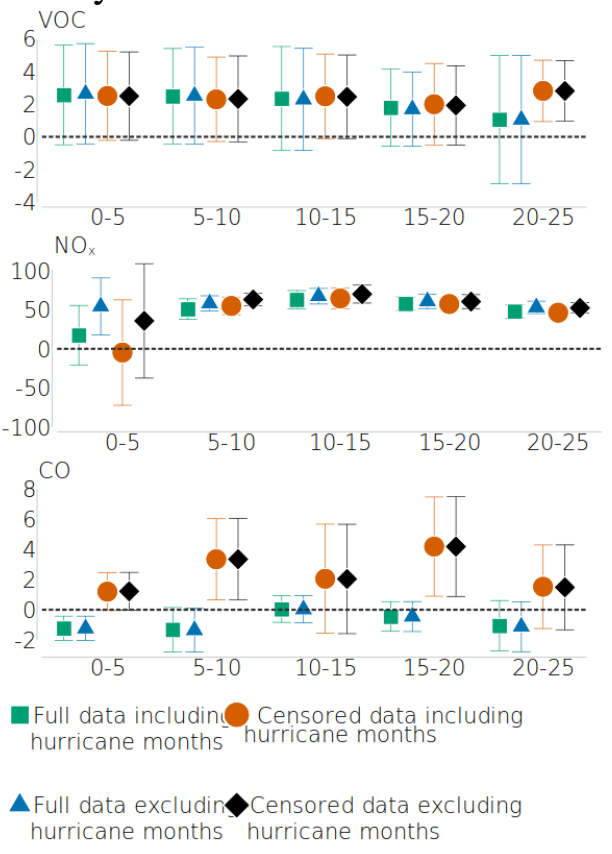

\section{B. Overlapping distance bins}
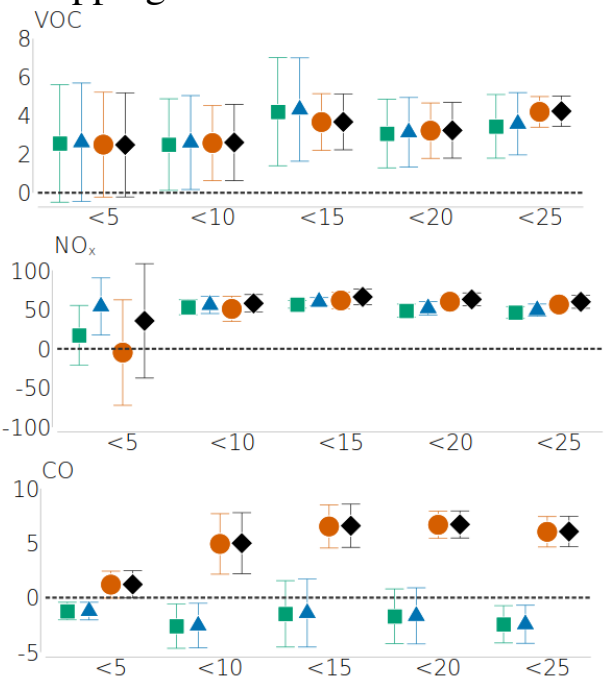

Full data includin Censored data including hurricane months hurricane months

$\Delta$ Full data excludin Censored data excluding hurricane months hurricane months

Note: This figure presents two sets of results that use the untransformed mean of daily ozone concentration as the dependent variable. Both sets of results, the left and right panel, use monitor by year fixed effects, week fixed effects and include weather variables. Brackets represent $95 \%$ confidence intervals, calculated from robust standard errors clustered at the monitor-level. There are four datasets used that vary across both the inclusion/exclusion of hurricane months and across the use of the full or censored excess emissions data. The full data include all emissions from every event while the censored data consider only the portion of emissions above the permitted level. Our preferred dataset and specification use the censored data that do not include hurricane months and use monitor-by-year fixed-effects. This combination is represented by the solid black diamond. The left panel considers mutually exclusive distance bins of 0-5 miles, 5-10 miles, etc. The right panel considers overlapping distance bins of 0-5 miles, 0-10 miles, etc. 
Figure A3: The estimated relationship between excess emissions and nearby daily ozone concentrations across different distance measures and model specifications.

\section{Effect on mean daily ozone concentration (ppb)}
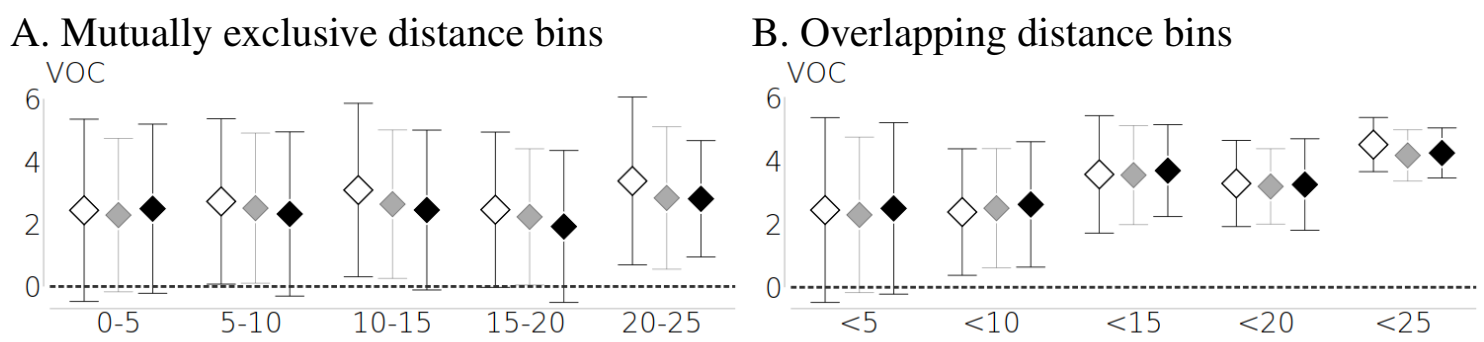

$\mathrm{NO}_{x}$
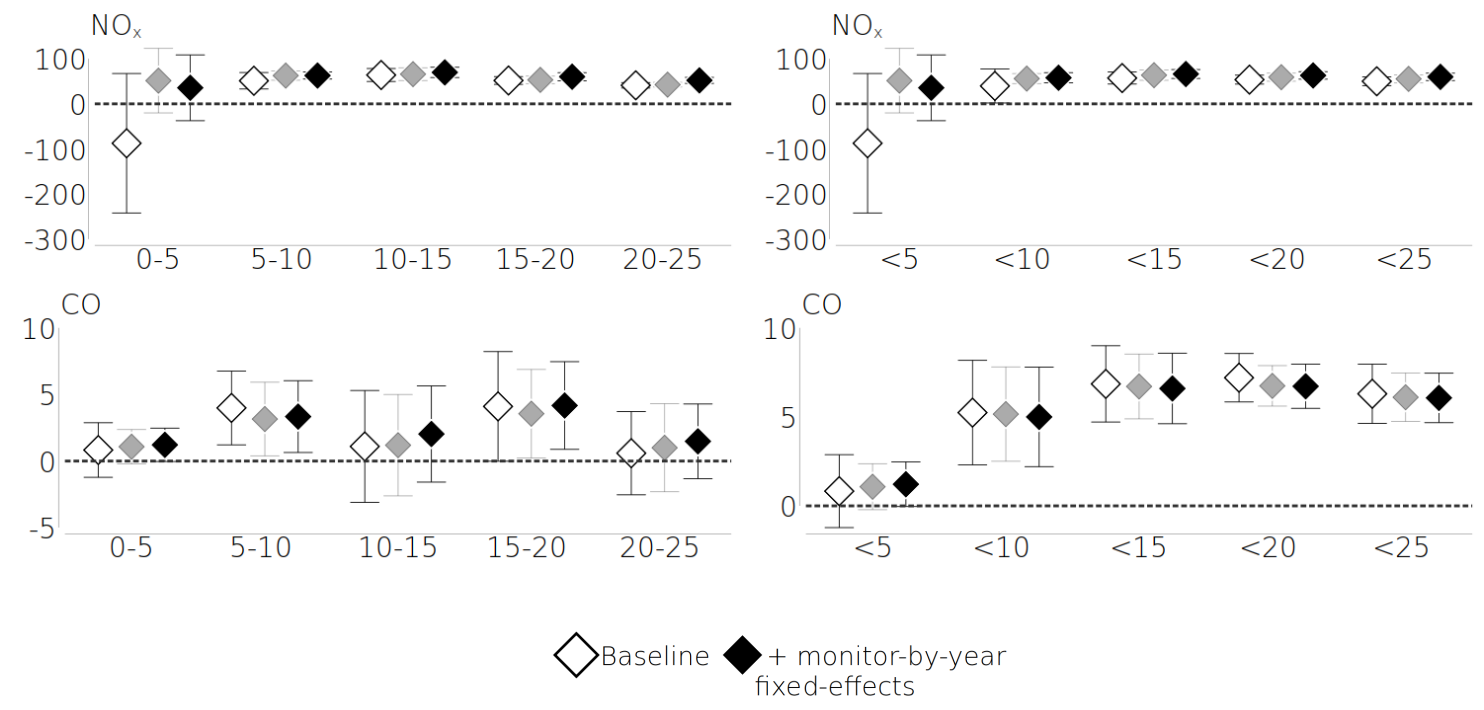

+ daily weather variables

Note: This figure presents two sets of results that use the untransformed mean of daily ozone concentration as the dependent variable. Both sets of results (both left and right panel) use the censored dataset, that excludes hurricane months. Brackets represent 95\% confidence intervals, calculated from robust standard errors clustered at the monitorlevel. The figure presents results from three model specifications. The first specification (labeled "Baseline", illustrated by the white diamond), uses monitor, week and year fixed effects. The second specification (labeled "+ daily weather variables", illustrated by the grey diamond), adds daily observations on temperature, precipitable water, relative humidity, atmospheric pressure, and wind speed. Our preferred specification (labeled "+ monitor-by-year fixed effects" illustrated by the black diamond) uses monitor by year as well as week fixed effects, in addition to the daily weather variables. The left panel considers mutually exclusive distance bins of 0-5 miles, 5-10 miles, etc. The right panel considers overlapping distance bins of 0-5 miles, 0-10 miles, etc. 
Table A5: Event study coefficients and standard errors from Figure 3

Effect on mean daily ozone concentration (ppb)

\begin{tabular}{|c|c|}
\hline & $\begin{array}{c}(1) \\
\text { Ozone (ppm) }\end{array}$ \\
\hline-6 and less & $\begin{array}{c}-0.33 \\
(0.28)\end{array}$ \\
\hline-5 & $\begin{array}{l}-0.37 \\
(0.22)\end{array}$ \\
\hline-4 & $\begin{array}{r}-0.56^{*} \\
(0.32)\end{array}$ \\
\hline-3 & $\begin{array}{c}0.01 \\
(0.27)\end{array}$ \\
\hline-2 & $\begin{array}{l}-0.09 \\
(0.21)\end{array}$ \\
\hline 0 & $\begin{array}{c}0.68 \\
(0.42)\end{array}$ \\
\hline+1 & $\begin{array}{l}0.68^{* *} \\
(0.29)\end{array}$ \\
\hline+2 & $\begin{array}{c}0.38 \\
(0.28)\end{array}$ \\
\hline+3 & $\begin{array}{c}0.22 \\
(0.27)\end{array}$ \\
\hline+4 & $\begin{array}{l}-0.21 \\
(0.35)\end{array}$ \\
\hline+5 & $\begin{array}{l}-0.50 \\
(0.36)\end{array}$ \\
\hline+6 and larger & $\begin{array}{l}-0.32 \\
(0.26)\end{array}$ \\
\hline Weather controls & Yes \\
\hline Monitor-by-year fixed effects & Yes \\
\hline Week fixed effects & Yes \\
\hline Cluster level & Monitor \\
\hline Observations & 406314 \\
\hline
\end{tabular}

Note: Numbers index days since most recent large excess emissions event. A large event means that the excess emission event is in the $95^{\text {th }}$ percentile by total tons of pollutants emitted. $* \mathrm{p}<0.1, * * \mathrm{p}<0.05$, *** $\mathrm{p}<0.01$. Robust standard errors clustered at the monitor level in parentheses. All regressions control for daily weather, monitor by year fixed effects, and week fixed effects. 
Figure A4: Placebo tests of the effect of excess emissions on ozone, for pollutants that are unrelated to mean daily ozone concentrations

\section{Effect on mean daily ozone concentration (ppb)}
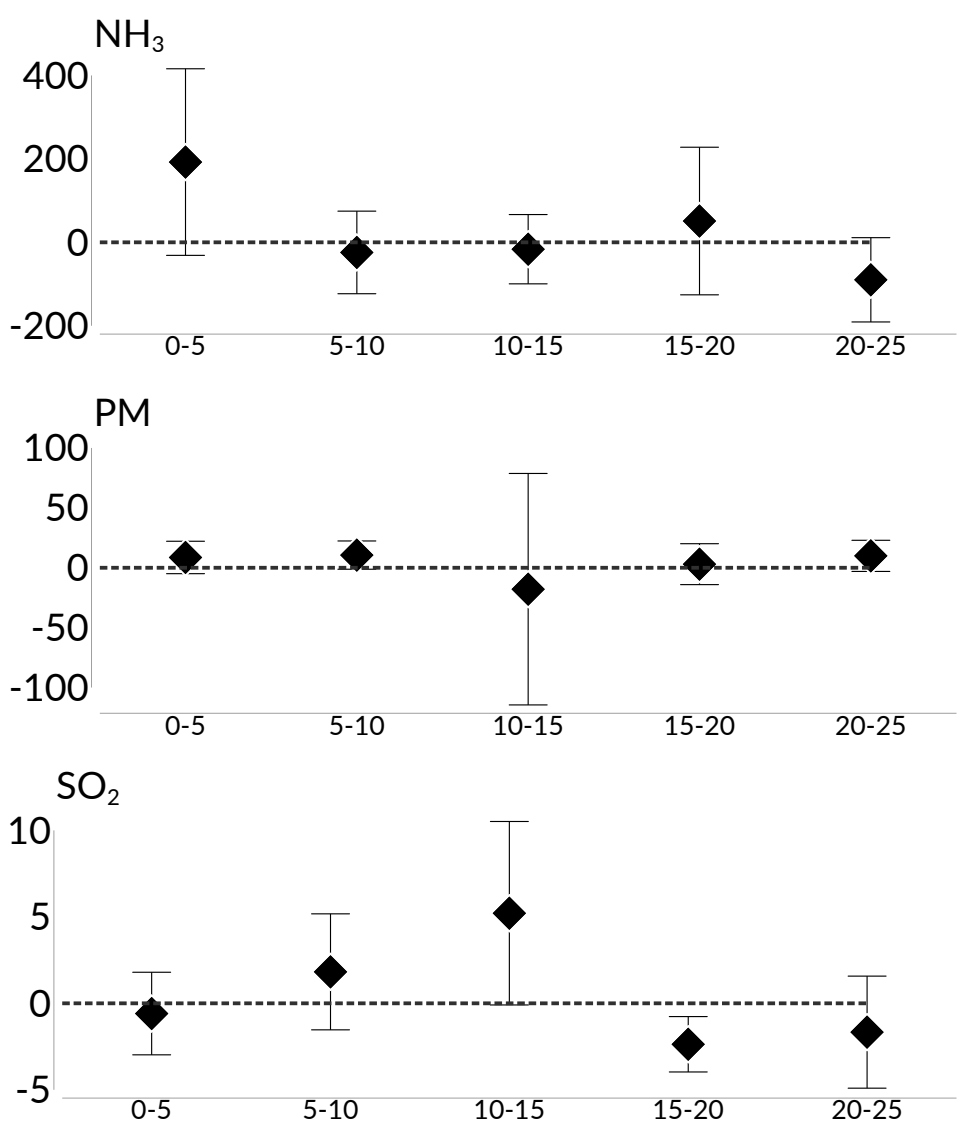

Note: All regressions use the full specification (monitor by year fixed effects, week fixed effects and weather variables included). Brackets represent $95 \%$ confidence intervals, calculated from robust standard errors clustered at the monitor-level. All regressions use the censored dataset that drops hurricane months. The distances are mutually exclusive distance bins of 0-5 miles, 5-10 miles, etc. 
Figure A5: The estimated relationship between excess emissions and all-cause mortality rate using different datasets and transforms of the dependent variable.

Effect on death rate transformed using:

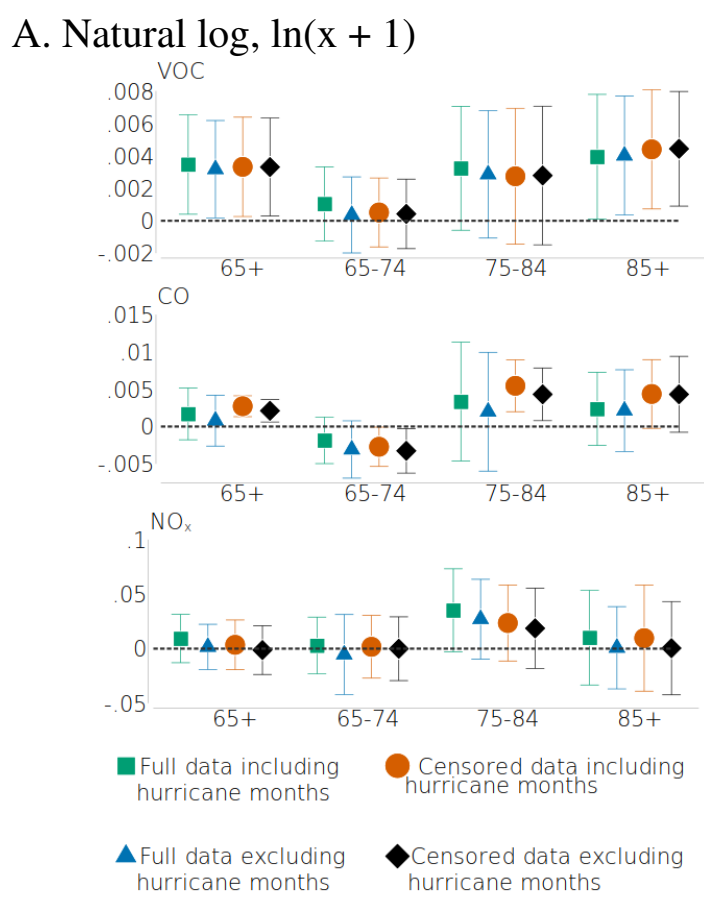

B. Inverse hyperbolic sine, $\operatorname{asinh}(\mathrm{x})$
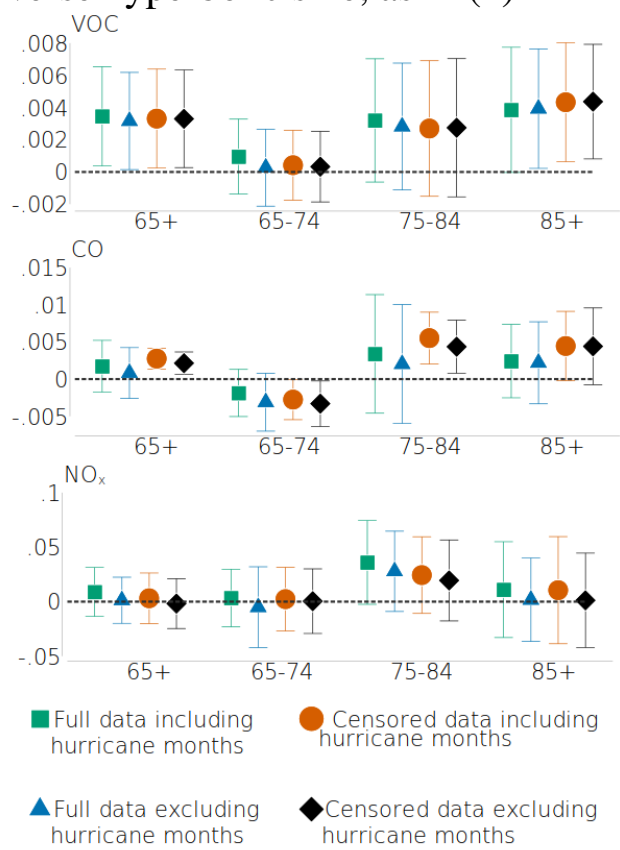

Note: Brackets represent $95 \%$ confidence intervals, calculated from robust standard errors clustered at the countylevel. All specifications in this figure represent our preferred model including county-by-year fixed-effects, and month fixed-effects. The shape and color of the marker reflect the dataset used. There are four datasets used that vary across both the inclusion/exclusion of hurricane months and across the use of the full or censored excess emissions data. The full data include all emissions from every event while the censored data consider only the portion of emissions above the permitted level. Our preferred dataset, represented by the black diamond, uses the censored data and does not include hurricane months. The dependent variable is the all-cause mortality per 100k. The left panel uses the natural $\log$ of the death rate plus one, while the right panel uses the inverse hyperbolic sine of death rate. 
Figure A6: The estimated relationship between excess emissions and all-cause mortality rate across different specifications and transforms of the dependent variable.

\section{Effect on death rate per 100,000:}
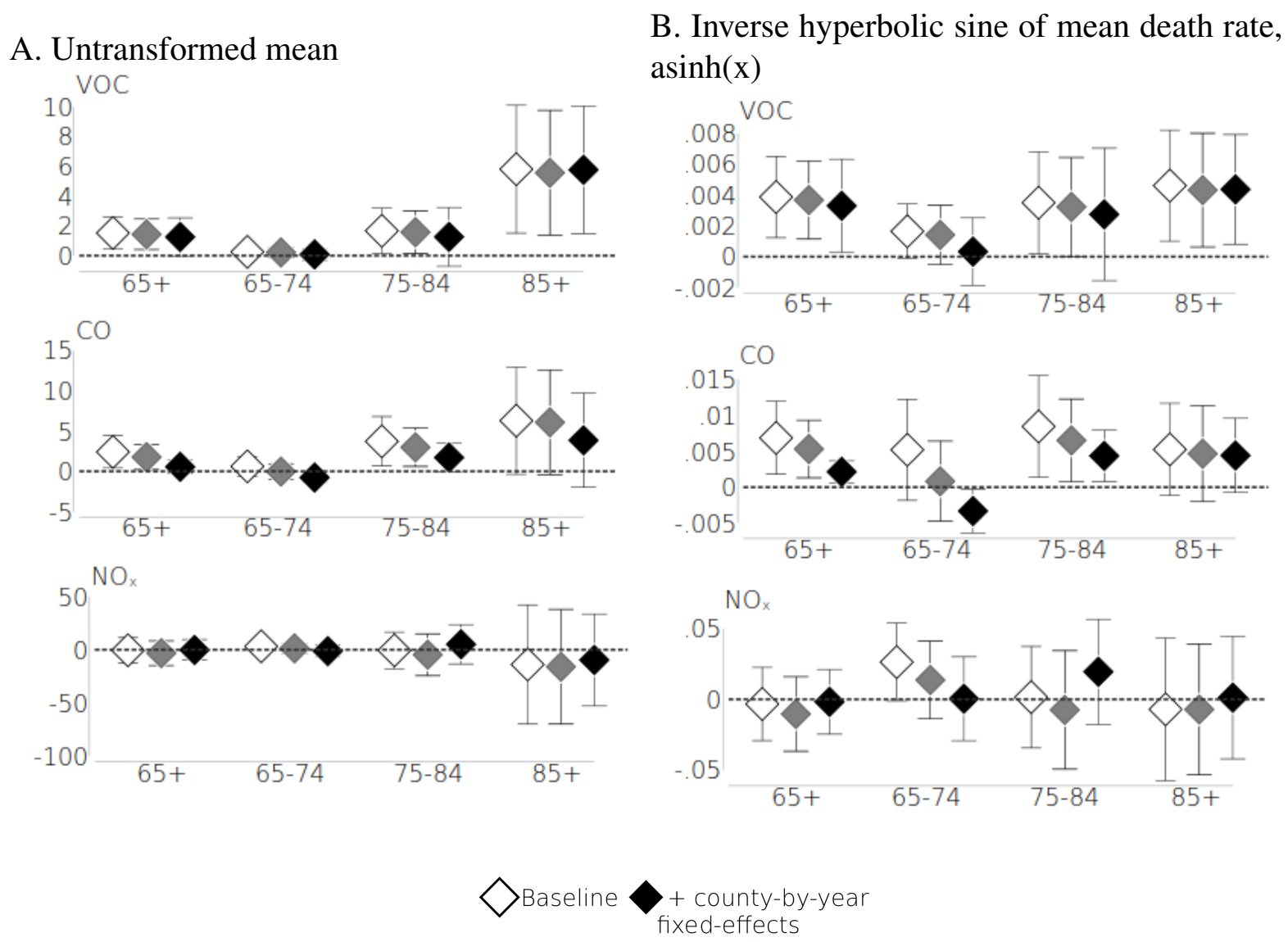

+ county-year controls

Note: Brackets represent 95\% confidence intervals, calculated from robust standard errors clustered at the county-level. All specifications in this figure represent our preferred dataset which includes only the portion of excess emissions above the permitted threshold (censored data) and excludes hurricane months. The shading of the marker reflects the specification used. The hollow shade represents the baseline specification that only includes county, year, and month fixed-effects. The midshade represents a specification that adds annual county-specific controls to the baseline, which include the unemployment rate, median income, $\%$ non-white, \% Hispanic origin, $\%$ elderly, $\%$ in poverty, and tons of lead emitted from TRI sources. The darkest shade uses county-by-year and month fixed-effects. The left panel uses the untransformed mean, while the right panel uses the inverse hyperbolic sine of mean death rate. 
Figure A7: Mortality increase from 1 ton of excess emissions by pollutant and age group.

Effect on death rate per 100,000
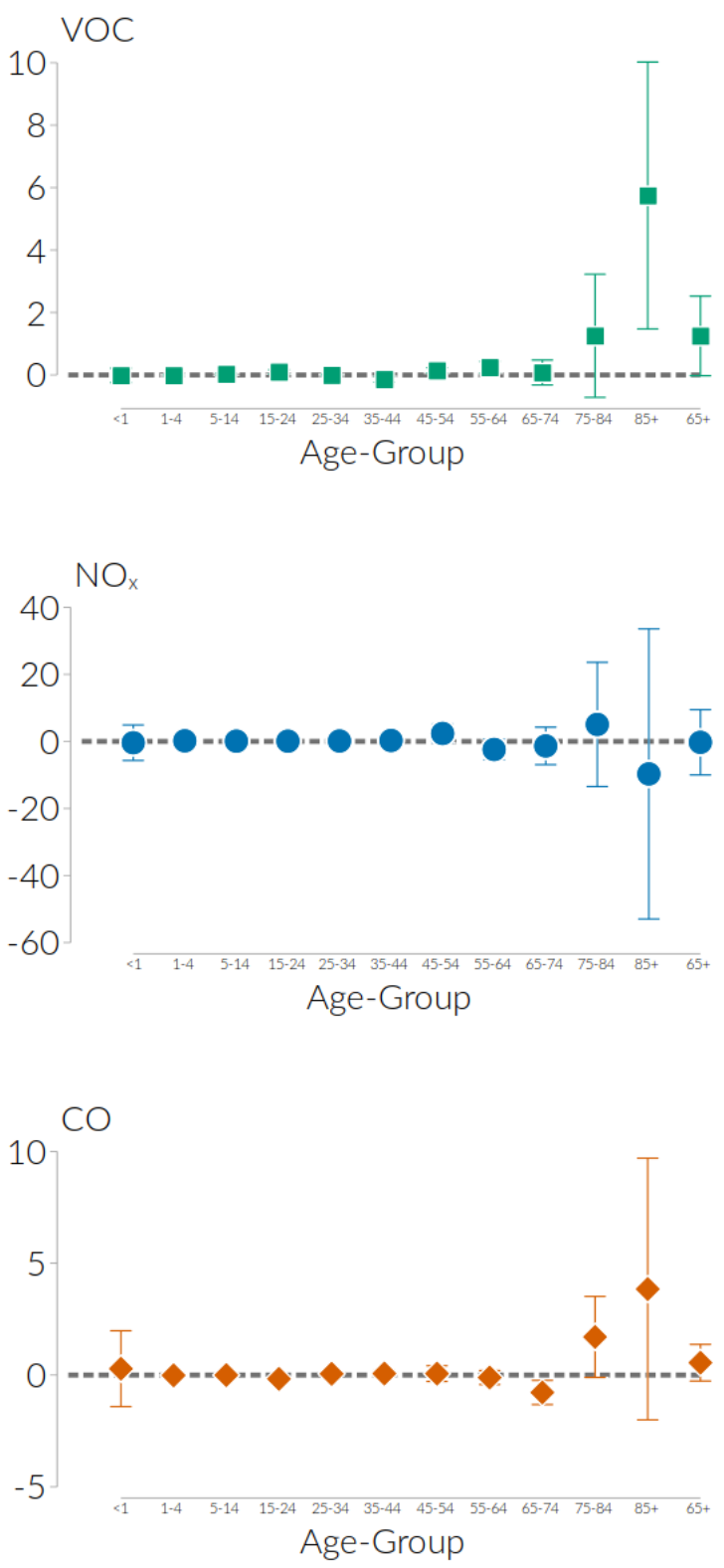

Note: Coefficients for each respective age group come from separate regressions. In each regression, the dependent variable is the death rate per 100,000 population of the age group. The independent variable differs by panel and is the tons of pollutant released from excess emissions events in a given county-month. Brackets indicate $95 \%$ confidence intervals, which are calculated using standard errors that are clustered at the county level. Each regression is weighted by the population of the sub group of interest. All regressions include county by year fixed effects, month fixed effects, and control for monthly weather variables. 
Table A6: Excess emissions and specific causes of death.

\begin{tabular}{|c|c|c|c|c|c|c|c|c|}
\hline & \multicolumn{2}{|c|}{$65+$} & \multicolumn{2}{|c|}{$65-74$} & \multicolumn{2}{|c|}{ 75-84 } & \multicolumn{2}{|c|}{$85+$} \\
\hline & Cardiovascular & Respiratory & Cardiovascular & Respiratory & Cardiovascular & Respiratory & Cardiovascular & Respiratory \\
\hline Excess VOC, 100 tons & $\begin{array}{c}0.584 \\
(0.397)\end{array}$ & $\begin{array}{c}0.245 \\
(0.166)\end{array}$ & $\begin{array}{c}0.092 \\
(0.273)\end{array}$ & $\begin{array}{c}0.089 \\
(0.134)\end{array}$ & $\begin{array}{l}0.841 \text { ** } \\
(0.330)\end{array}$ & $\begin{array}{c}0.364 \\
(0.255)\end{array}$ & $\begin{array}{c}2.024 \\
(1.521)\end{array}$ & $\begin{array}{c}0.279 \\
(0.963)\end{array}$ \\
\hline Excess $\mathrm{NO}_{x}, 100$ tons & $\begin{array}{c}-1.883 \\
(2.611)\end{array}$ & $\begin{array}{l}-4.979^{* * * *} \\
(1.694)\end{array}$ & $\begin{array}{c}0.580 \\
(2.037)\end{array}$ & $\begin{array}{l}-2.461 \\
(1.521)\end{array}$ & $\begin{array}{c}1.242 \\
(4.871)\end{array}$ & $\begin{array}{l}-6.122 \\
(3.977)\end{array}$ & $\begin{array}{l}-24.612 \\
(22.275)\end{array}$ & $\begin{array}{r}-11.659 \\
(7.575)\end{array}$ \\
\hline Excess $\mathrm{CO}, 100$ tons & $\begin{array}{c}0.189 \\
(0.567)\end{array}$ & $\begin{array}{c}0.015 \\
(0.151)\end{array}$ & $\begin{array}{l}-0.588^{*} \\
(0.319)\end{array}$ & $\begin{array}{c}0.025 \\
(0.141)\end{array}$ & $\begin{array}{c}1.346 \\
(0.824)\end{array}$ & $\begin{array}{c}0.173 \\
(0.337)\end{array}$ & $\begin{array}{c}0.844 \\
(1.591)\end{array}$ & $\begin{array}{l}-0.205 \\
(0.997)\end{array}$ \\
\hline Mean monthly death rate per $100 \mathrm{k}$ & 151.07 & 49.46 & 56.49 & 22.51 & 155.38 & 57.70 & 545.31 & 139.33 \\
\hline County-by-year fixed-effects & Yes & Yes & Yes & Yes & Yes & Yes & Yes & Yes \\
\hline Month fixed-effects & Yes & Yes & Yes & Yes & Yes & Yes & Yes & Yes \\
\hline Hurricane months included & No & No & No & No & No & No & No & No \\
\hline Censored dataset & Yes & Yes & Yes & Yes & Yes & Yes & Yes & Yes \\
\hline County clustered standard errors & Yes & Yes & Yes & Yes & Yes & Yes & Yes & Yes \\
\hline Adj. $R^{2}$ & 0.37 & 0.20 & 0.14 & 0.10 & 0.19 & 0.09 & 0.20 & 0.08 \\
\hline Observations & 45069 & 45069 & 44549 & 44549 & 44668 & 44668 & 44553 & 44553 \\
\hline
\end{tabular}

Note: $* \mathrm{p}<0.1, * * \mathrm{p}<0.05,{ }^{* * *} \mathrm{p}<0.01$. Robust standard errors clustered at the county-level are reported in parentheses. Each regression is weighted by the county population of the relevant subgroup.

Table A7: Excess emissions and all-cause elderly mortality by age group Effect on death rate per 100,000

\begin{tabular}{lcccc}
\hline & $65+$ & $65-74$ & $75-84$ & $85+$ \\
\hline Excess VOC, 100 tons & $1.156^{*}$ & 0.041 & 1.202 & $5.401 * * *$ \\
& $(0.613)$ & $(0.195)$ & $(0.973)$ & $(1.970)$ \\
Excess $\mathrm{NO}_{x}, 100$ tons & -2.025 & -2.083 & 3.038 & -14.885 \\
& $(5.129)$ & $(2.964)$ & $(9.812)$ & $(21.200)$ \\
Excess CO, 100 tons & 0.671 & $-0.712^{* *}$ & $1.832^{*}$ & 4.034 \\
& $(0.473)$ & $(0.291)$ & $(0.971)$ & $(3.022)$ \\
\hline Mean monthly death rate per 100k & 409.45 & 182.45 & 440.58 & 1280.31 \\
\hline Adj. $\mathrm{R}^{2}$ & 0.39 & 0.22 & 0.21 & 0.19 \\
Observations & 44658 & 44150 & 44266 & 44151 \\
\hline
\end{tabular}

Note: $* \mathrm{p}<0.1, * * \mathrm{p}<0.05, * * * \mathrm{p}<0.01$. Robust standard errors clustered at the county level in parentheses. Each regression is weighted by the county population of the relevant subgroup. 